\title{
Encoal Mild Coal Gasification Project: Commercial Plant Feasibility Study
}

\author{
Topical Report \\ July 1997
}

Work Performed Under Contract No.: DE-FC21-90MC27339

For

U.S. Department of Energy

Office of Fossil Energy

Federal Energy Technology Center

Morgantown Site

P.O. Box 880

Morgantown, West Virginia 26507-0880

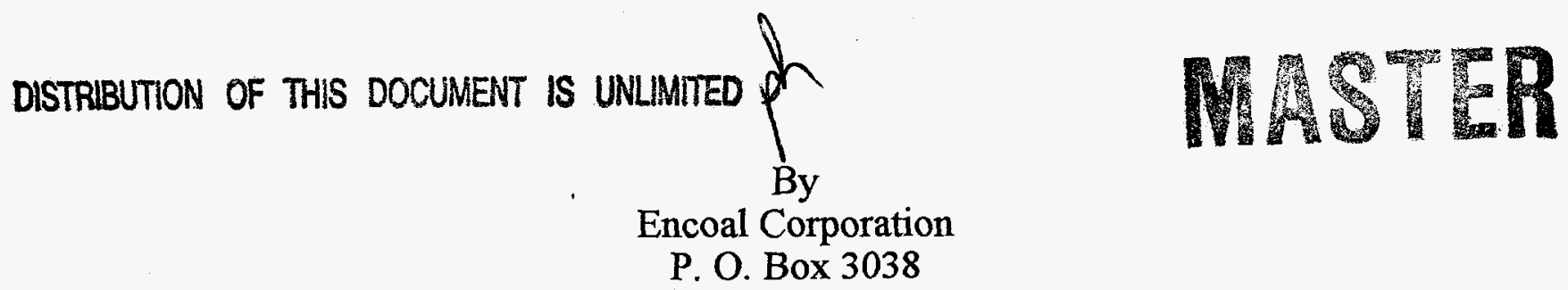

Gillette, Wyoming 82717-3038 


\section{Disclaimer}

This report was prepared as an account of work sponsored by an agency of the United States Government. Neither the United States Government nor any agency thereof, nor any of their employees, makes any warranty, express or implied, or assumes any legal liability or responsibility for the accuracy, completeness, or usefulness of any information, apparatus, product, or process disclosed, or represents that its use would not infringe privately owned rights. Reference herein to any specific commercial product, process, or service by trade name, trademark, manufacturer, or otherwise does not necessarily constitute or imply its endorsement, recommendation, or favoring by the United States Government or any agency thereof. The views and opinions of authors expressed herein do not necessarily state or reflect those of the United States Government or any agency thereof. 


\section{DISCLAIMER}

Portions of this document may be illegible electronic image products. Images are produced from the best available original document. 


\section{TRADEMARK NOTICE}

LFC $®, E N C O A L \circledast$, PDF® and CDL® are registered trademarks of the TEK-KOL Partnership that describe the process, technical services and products associated with the LFC@ Technology developed and owned by TEK-KOL and its owners, SGI International and Zeigler Coal Holding Company. For simplification and readability purposes, the trademark symbols will not be used beyond this point in the attached paper. 


\section{ENCOAL MILD COAL GASIFICATION PROJECT: \\ COMMERCIAL PLANT FEASIBILITY STUDY}

\section{TABLE OF CONTENTS}

TRADEMARK NOTICE $\ldots \ldots \ldots \ldots \ldots \ldots \ldots \ldots \ldots \ldots \ldots \ldots \ldots$ ii

TABLE OF CONTENTS $\ldots \ldots \ldots \ldots \ldots \ldots \ldots \ldots \ldots \ldots \ldots \ldots \ldots \ldots \ldots \ldots \ldots \ldots$

LIST OF FIGURES $\ldots \ldots \ldots \ldots \ldots \ldots \ldots \ldots \ldots \ldots \ldots \ldots \ldots \ldots \ldots$ iv

LIST OF TABLES $\ldots \ldots \ldots \ldots \ldots \ldots \ldots \ldots \ldots \ldots \ldots \ldots \ldots \ldots \ldots \ldots \ldots$

Summary $\ldots \ldots \ldots \ldots \ldots \ldots \ldots \ldots \ldots \ldots \ldots \ldots \ldots \ldots \ldots \ldots \ldots \ldots \ldots \ldots \ldots$

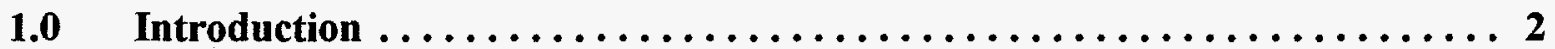

2.0 Mine and Infrastructure Assessment $\ldots \ldots \ldots \ldots \ldots \ldots \ldots \ldots \ldots \ldots$

3.0 Coal Sampling and Testing $\ldots \ldots \ldots \ldots \ldots \ldots \ldots \ldots \ldots \ldots \ldots \ldots$

$4.0 \quad$ Market Assessment of PDF and CDL $\ldots \ldots \ldots \ldots \ldots \ldots \ldots \ldots \ldots$

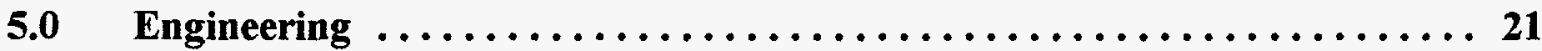

5.1 Introduction and Overview ............. 21

5.2 Process Flow Diagrams and Material Flow Balance ... 29

5.3 Equipment Lists and Equipment Data Sheets ...... 34

5.4 Site layout and Support Facilities ........... 36

5.5 Site Preparation and Drainage $\ldots \ldots \ldots \ldots \ldots \ldots \ldots$

5.6 Piping and Instrumentation Diagrams $\ldots \ldots \ldots \ldots 42$

5.7 Generic Subsystem Drawings $\ldots \ldots \ldots \ldots \ldots \ldots \ldots$

$5.8 \quad$ Plant Profile Drawings ................ 45

5.9 Electrical, Controls and Instrumentation . . . . . . 48

6.0 Environmental and Permit Requirements $\ldots \ldots \ldots \ldots \ldots \ldots \ldots \ldots$

7.0 Commercial Plant Implementation Schedule $\ldots \ldots \ldots \ldots \ldots \ldots \ldots \ldots$

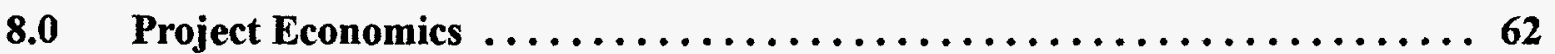

$9.0 \quad$ Project Risk Assessment $\ldots \ldots \ldots \ldots \ldots \ldots \ldots \ldots \ldots \ldots \ldots \ldots \ldots \ldots \ldots \ldots$

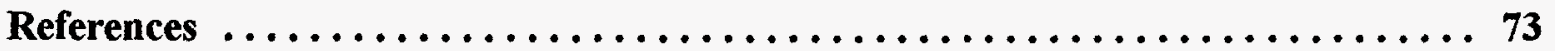

Glossary $\ldots \ldots \ldots \ldots \ldots \ldots \ldots \ldots \ldots \ldots \ldots \ldots \ldots \ldots \ldots \ldots \ldots \ldots \ldots \ldots \ldots$ 


\section{LIST OF FIGURES}

\section{PAGE}

Figure 2.1 North Rochelle Mine Location..$\ldots \ldots \ldots \ldots \ldots \ldots \ldots$

Figure 5.1.1 ENCOAL Plant Simplified Process Flow Diagram $\ldots \ldots \ldots \ldots \ldots 22$

Figure 5.1.2 PDF Deactivation (VFB) Loop Simplified Loop Diagram $\ldots \ldots \ldots 23$

Figure 5.1.3 PDF Finishing Loop Simplified Flow Diagram $\ldots \ldots \ldots \ldots \ldots \ldots$

Figure 5.1.4 Commercial Plant Concept Diagram $\ldots \ldots \ldots \ldots \ldots \ldots \ldots$

Figure 5.2.1 Commercial Plant LFC Module $\ldots \ldots \ldots \ldots \ldots \ldots \ldots \ldots \ldots, \ldots$

Figure 5.4.1 LFC Commercial Plant Plot Plan $\ldots \ldots \ldots \ldots \ldots \ldots \ldots \ldots \ldots$

Figure 5.8.1 LFC Commercial Plant Profile and Plan View ............46

Figure 5.9.1 Control Scheme $\ldots \ldots \ldots \ldots \ldots \ldots \ldots \ldots \ldots \ldots \ldots \ldots \ldots \ldots, \ldots \ldots \ldots$

Figure 7.1 Commercial Plant Implementation Schedule $\ldots \ldots \ldots \ldots \ldots \ldots 61$ 


\section{LIST OF TABLES}

PAGE

Table 3.1 Technical Screening Criteria Comparison $\ldots \ldots \ldots \ldots \ldots \ldots \ldots$

Table $3.2 \quad$ Run of Mine Coal Qualities $\ldots \ldots \ldots \ldots \ldots \ldots \ldots \ldots \ldots \ldots$

Table $3.3 \quad$ PDF Quality Comparison $\ldots \ldots \ldots \ldots \ldots \ldots \ldots \ldots \ldots \ldots \ldots$

Table $3.4 \quad$ CDL Quality Comparison $\ldots \ldots \ldots \ldots \ldots \ldots \ldots \ldots \ldots \ldots \ldots \ldots$

Table 4.1 Existing North American PCI/GCI Blast Furnaces

(December 1996) ........................... 18

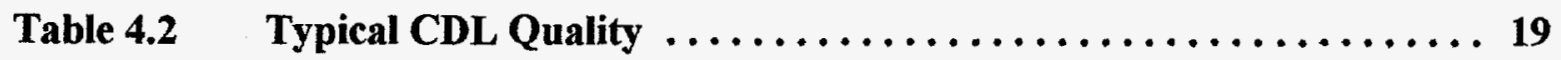

Table 5.1.1 TEK-KOL Intellectual Property Status (as of 3/12/97) . . . . . . . 28

Table 5.3.1 Index of Equipment Data Sheets $\ldots \ldots \ldots \ldots \ldots \ldots \ldots$

Table 5.4.1 Index of Structures and Buildings $\ldots \ldots \ldots \ldots \ldots \ldots \ldots \ldots$

Table $8.1 \quad$ Capital Cost Summary $\ldots \ldots \ldots \ldots \ldots \ldots \ldots \ldots \ldots \ldots \ldots \ldots$

Table $8.2 \quad$ Operating Costs at Full Production $\ldots \ldots \ldots \ldots \ldots \ldots \ldots$

Table $8.3 \quad$ Significant Assumptions $\ldots \ldots \ldots \ldots \ldots \ldots \ldots \ldots \ldots \ldots \ldots \ldots$

Table $8.4 \quad$ Commercial Plant Economics Summary $\ldots \ldots \ldots \ldots \ldots \ldots \ldots$ 


\section{ENCOAL MILD COAL GASIFICATION PROJECT: COMMERCIAL PLANT FEASIBILITY STUDY}

\section{Summary}

In order to determine the viability of any Liquids from Coal (LFC) commercial venture, TEK-KOL and its partner, Mitsubishi Heavy Industries (MHI), have put together a technical and economic feasibility study for a commercial-size LFC Plant located at Zeigler Coal Holding Company's North Rochelle Mine site.

This resulting document, the ENCOAL Mild Coal Gasification Plant: Commercial Plant Feasibility Study, includes basic plant design, capital estimates, market assessment for coproducts, operating cost assessments, and overall financial evaluation for a generic Powder River Basin based plant. This document and format closely resembles a typical Phase II study as assembled by the TEK-KOL Partnership to evaluate potential sites for LFC commercial facilities around the world. 


\section{Section 1.0 Introduction}

The TEK-KOL Partnership (TEK-KOL), a Partnership between SGI International (SGI) and a unit of Zeigler Coal Holding Company (ZCHC), is proposing the development of a commercial-scale LFC plant in the Powder River Basin (PRB) of Wyoming. The LFC Commercial Plant concept consists of three 5,000-metric ton/day parallel modules that will convert 15,000 metric tons/day of low-sulfur, low-ash, low-Btu Powder River Basin coal into Process Derived Fuel (PDF) and Coal Derived Liquid (CDL). PDF is a high-Btu, clean-burning solid fuel or carbon source produced through the LFC mild pyrolysis process. CDL is a low-sulfur hydrocarbon liquid that is a valuable fuel, and its components have value as chemical feedstock. These coproducts possess desirable characteristics and considerable market potential.

TEK-KOL is seeking potential project participants to detail design, construct and operate the Commercial Plant Project.

To demonstrate the LFC technology, ENCOAL Corporation (ENCOAL), a wholly-owned subsidiary of Zeigler Coal Holding Company, designed, constructed and is operating a 1,000-ton/day LFC Plant in Gillette, Wyoming. The Plant has demonstrated the LFC Process and the product values of CDL and PDF. The ENCOAL Plant was designed, constructed and operated for a budget cost of $\$ 90$ million in cooperation with the U.S. Department of Energy under Round Three of the Clean Coal Technology Program. Operation of the ENCOAL Plant has provided much of the basis for estimating operating cost, design basis, and product market data for the Study. Unlike most coal upgrading projects, full-scale shipment and test burns were made possible by the near-commercial size of the ENCOAL Plant. An ENCOAL project history is included in Section 5.1.

The ENCOAL operating experience was also used for the design basis and capital estimates for the LFC Commercial Plant. In mid-1995, MHI and TEK-KOL engineering staffs initiated a Design and Engineering Cost Estimate for an LFC Commercial Plant located in the Powder River Basin. In February 1996, this arrangement was formalized in an agreement or Memorandum of Understanding signed by MHI and both TEK-KOL partners. The Commercial Plant Feasibility Study (Study) represents a significant engineering effort on behalf of MHI and TEK-KOL. The Study was completed in March 1996, and updated later in the same year. This document reports the results of this Study as of December 1996. 


\section{Process Description}

The high moisture content of Powder River Basin coal accounts for its low heating value. Powder River Basin coals normally have moisture contents of 25 to $32 \%$ with heating value ranging from $8000 \mathrm{Btu} /$ pound to $8700 \mathrm{Btu} /$ pound. The LFC Process first dries the mined coal to very nearly zero moisture. The dried coal is then mildly pyrolyzed, and approximately $60 \%$ of the original volatile matter and a portion of the sulfur are removed. Unlike many coal cleaning or coal upgrading processes, these two steps physically and chemically alter the basic coal characteristics. This metamorphosis helps to eliminate many of the problems associated with coal drying. The coal char is then finished in a multiple-step process adding moisture, oxygen and cooling the char to finally produce PDF.

Volatile matter driven off during the pyrolysis process is partially condensed in a multiple-step process that produces the hydrocarbon liquid CDL. The noncondensed or collected hydrocarbon is returned to the process combustors as a heat source for the drying and pyrolyzing steps. Each ton of raw feed North Rochelle coal will produce approximately $1 / 2$ ton of PDF, $1 / 2$ barrel of CDL, and will account directly for $70 \%$ of the process gas requirements.

TEK-KOL believes that the project will benefit from a number of intrinsic economic advantages:

1. $\quad \mathrm{PDF}$ and $\mathrm{CDL}$ are clean-burning fuels.

2. PDF has multiple market applications in utilities and steelmaking.

3. The decline of coking ovens in the United States has reduced the supply of coal liquids and increased the potential market for PDF in steelmaking.

A number of factors make PDF an increasingly valuable boiler fuel: PDF has distinct transportation advantages, it is readily available, competitively priced fuel, and it has low sulfur content, low $\mathrm{NO}_{\mathrm{x}}$ emissions and low ash fusion temperatures. Proposed electric utility deregulation and potential $\mathrm{NO}_{\mathrm{x}}$ emission regulation may make PDF an even more attractive fuel choice in the future. Also, as high costs and environmental problems continue to shut down coke ovens, the steel industry is replacing coke in blast furnaces with Pulverized Coal Injection (PCI). PDF may become a viable injected fuel for these blast furnaces. In the use of Direct Reduction of Iron (DRI) to produce steel, PDF appears to be an excellent alternative source of carbon and fuel.

$\mathrm{CDL}$ is a highly aromatic coal liquid that has found some acceptance in the residual fuels market in the United States. Low natural gas prices and an abundance of heavy oils, however, have kept this market depressed during the ENCOAL Plant demonstration period. This has led TEK-KOL to pursue the higher value CDL fractions that are described in this Study.

Detailed project economics and financial analysis can be located in Section 9 of this Study. It is anticipated that the capital investment for the described project scope will be $\$ 475$ million with an unleveraged rate of return in the 14 to $15 \%$ range. 


\section{Section 2.0 Mine and Infrastructure Assessment}

\section{Introduction and Summary}

The North Rochelle Mine is currently being operated on a small scale but is being developed to a full-scale mine by Triton Coal Company. Triton Coal, a subsidiary of Zeigler Coal Holding Company, operates the Buckskin Mine located 10 miles north of Gillette, Wyoming, and is a well-established coal operator.

The North Rochelle mine is located in the Powder River Basin of northeastern Wyoming, currently the largest coal-producing region in the Unites States. North Rochelle is located approximately 60 miles south of Gillette, Wyoming, along the east flank of the Powder River Basin. Its general location is shown in Figure 2.1.

The North Rochelle Mine reserve is classified as a subbituminous coal with a very low sulfur content. Mineable reserves total 172 million tons and extend over the majority of the 1,960-acre federal lease area and adjacent 80-acre feed coal area. To expand this reserve base, Triton has filed a lease-byapplication for an adjacent federal lease area that includes 150 million recoverable tons of coal. Minor amounts of coal have been produced from North Rochelle over the last several years to meet due diligence requirements of the federal coal lease. Triton recently announced that full-scale development will begin in 1997 with initial commercial production slated for late 1998.

The equipment planned for the North Rochelle Mine will be adequate to meet the coal production forecast of 15 million tons/year in 1999. Some risk to the LFC plant is involved because at this production rate, the mine will have a life of less than 25 years. This risk can be mitigated by either leasing additional reserves adjacent to North Rochelle or by supplying the plant from several other mines in the immediate area.

\section{Data}

\section{Geological Conditions and Coal Resources}

The North Rochelle Mine Area is located along the eastern flank of the Powder River Basin. Geologic formations in the Powder River Basin are of sedimentary origin, ranging from the Pre-Cambrian age to the lower Tertiary System and are probably less than 100 million years old. Rocks in the eastern and central portion of the Basin generally strike north-south and have very slight dips, usually less than 3 degrees toward the west.

Mining will disturb sediments ranging from the Paleocene Age Fort Union Formation to Holocene Age colluvium and alluvium. The coal to be mined occurs in the uppermost portion of the Fort Union Formation. The overburden lithologic units present in the mine area consist of alternating shale, sandstone, siltstone and coal of the Wasatch Formation. 
The two mineable seams of coal in the area belong to the Tongue River Member of the Fort Union Formation. The Lower Canyon Seam of the Wyodak Bed is identified as the main or "E" seam. The rider seam or "D2" seam is believed to be an extension of the Anderson Seam, the upper seam in the Wyodak Bed. Thin carbonaceous stringers are found in the Wasatch Formation above the coal seams but are of limited extent and poor quality.

The main coal seam is located at a depth of about 110 feet on the southeast side of the mine area, and about 290 feet below the surface on the west side. The average overburden thickness is 207 feet. The main seam varies from 40 to 70 feet thick, and within the mine area it is fairly uniform, averaging 61 feet.

The rider coal seam above the main seam varies from less than 1 foot to over 8 feet in thickness, and is not continuous over the entire mine area. It will be mined in the northern section of the mine area where it averages 7 feet thick and is separated from the main seam by 3 to 10 feet of interburden.

Triton estimates that approximately 172 million tons of coal can be recovered from the mine area. The main seam accounts for the majority of the recoverable coal with 170 million tons. About 2 million tons of the minor seam are recoverable due to sporadic thickness and quality.

Geotechnical

Geotechnical studies were completed in 1982 for the North Rochelle Mine facilities design. This same information forms the basis for foundation design for the LFC Commercial Plant.

\section{Coal Quality}

The weighted average as-received quality for the recoverable reserves is outlined below.

\section{As-Received Basis}

$\begin{array}{lr}\text { \% Moisture } & 27.00 \\ \text { \% Volatile Matter } & 31.60 \\ \text { \% Fixed Carbon } & 36.70 \\ \text { \% Ash } & 4.70 \\ \text { \% Sulfur } & 0.23 \\ \text { Btu/pound } & 8,750\end{array}$

Because of its very low sulfur content, the North Rochelle coal is classified informally as a "supercompliance" coal. 
Figure 2.1: North Rochelle Mine Location

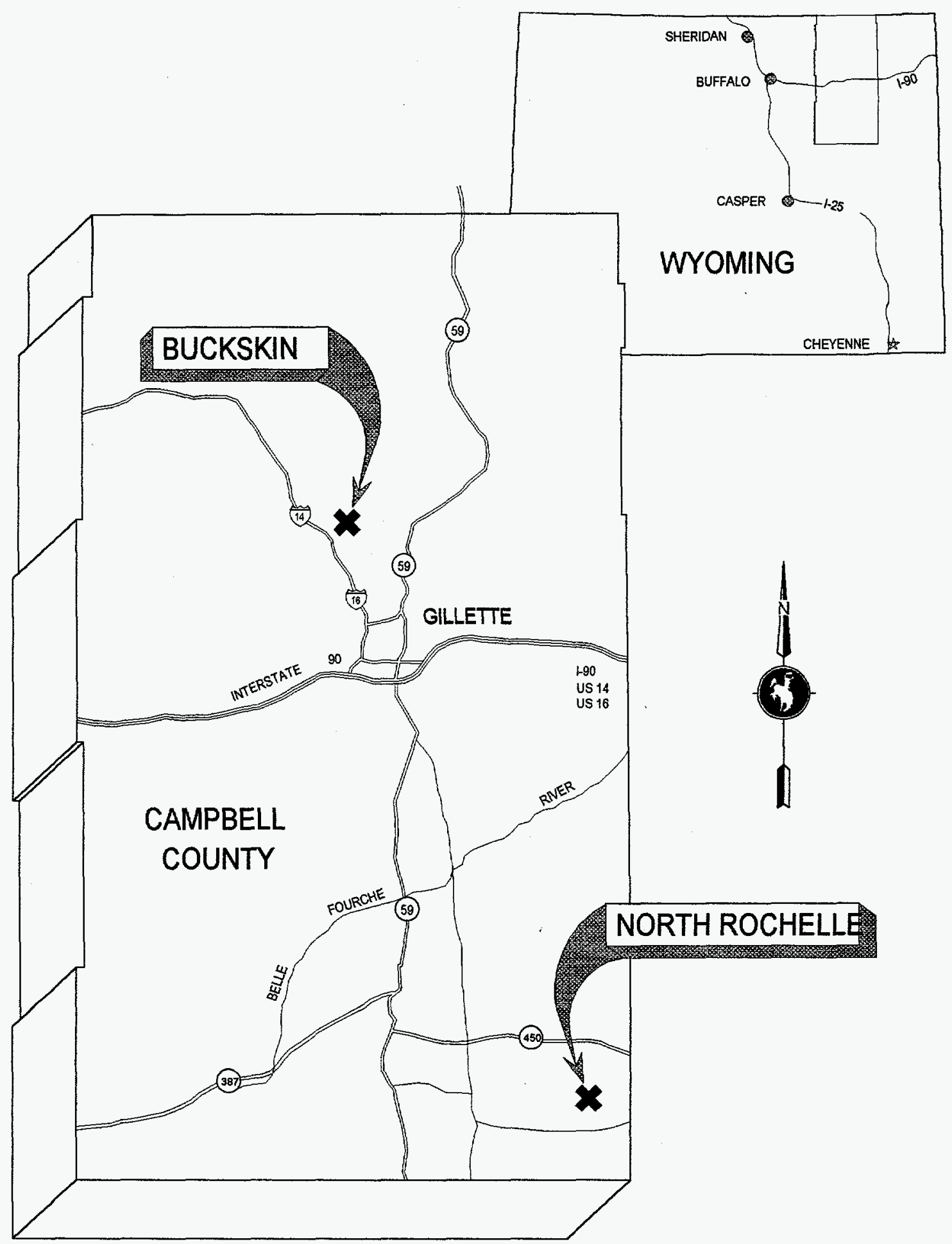




\section{Section 3.0 Coal Sampling and Testing}

\section{Summary}

In order to determine the suitability of a candidate coal for LFC upgrading, the coal is subjected to the same three-step evaluation process that was use to determine the applicability of the LFC technology to Buckskin Mine coal. Because the ENCOAL Plant has been extremely successful in processing this type of subbituminous coal, the evaluation process is considered to be a very reliable predictor.

Successful completion of the evaluation process has determined that Powder River Basin coal is a good candidate for upgrading using the LFC technology. Additionally, because of the similarities between North Rochelle and Buckskin coals, there is a very high level of confidence in the ability to apply experience gained at the ENCOAL Plant to the processing of Powder River Basin coal in an LFC facility. Also, based on the effectiveness of the three-step laboratory evaluation process and the success of the ENCOAL Plant, a full-scale plant test of candidate coals similar to Buckskin coal is not required.

\section{Introduction}

Not all low-rank subbituminous and lignite coals are suitable for upgrading utilizing the LFC technology. In order to identify suitable candidates, a sequential evaluation process is employed.

In the first step, the candidate coal's physical and chemical properties are compared to technical screening criteria. Good agreement with the screening criteria strongly suggests success will be achieved in the next phase of testing. Table 3.1 details these criteria. The significance of these criteria and the respective values are as follows:

- High moisture content adds more value by upgrading.

- Low ash content is required because the ash remains in the solid product, PDF.

- The lower the fuel ratio, the greater the amount of volatile mater available for recovery as CDL.

- The $\mathrm{H} / \mathrm{C}$ ratio needs to be high in order to ensure volatile matter will evolve with a high percentage of recoverable hydrocarbon vapor and not oxygen based gases (i.e., carbon dioxide and carbon monoxide).

- Free swelling is an important consideration concerning coal handling and processing in the drying and pyrolyzing stages of the LFC process. 
The second step in the evaluation process is referred to as the Phase I Technical Feasibility Study. This employs small-sample testing of the candidate coal in a thermogravimetric analyzer (TGA), where the sample is subjected to mild gasification conditions. Fourier Transform Infrared (FTIR) spectroscopy is used to analyze the gases generated during the testing. Combining FTIR results with proximate and ultimate data for the as-received coal and the residual solid product (char) facilitates generation of a mass balance suitable for preliminary LFC plant design. Successful completion of this step demonstrates the technical feasibility of using the LFC process for upgrading the candidate coal.

A Phase II Study is the third step in the evaluation process and is intended to demonstrate the viability of a commercial-scale LFC project. This step employs large-scale sample testing in a Sample Preparation Unit (SPU) equipped with a CDL recovery system and FTIR analytical capability for gas analysis. The SPU provides the necessary quantities of liquid CDL and solid PDF for a detailed product analysis: in turn, this analysis provides data for an accurate mass balance and for product marketing assessments. In addition to a budgetary plant design and marketing study, the Phase II Study also includes operating cost analysis, plant site and infrastructure assessment, and financial analysis.

\section{Data Section}

In leu of large-scale sample testing in the SPU, an alternate coal test was conducted at the ENCOAL plant to provide the necessary data for the Phase II Study. In October and November 1995, nearly 5,000 tons of North Rochelle Mine coal was transported via truck to the Buckskin Mine for processing in the ENCOAL plant. After screening to $2 \times 1 / 8$ inch size, approximately 2,500 tons of coal was processed between November $21^{\text {st }}$ and November $26^{\text {th }}, 1995$. A summary of parameters for the North Rochelle coal tested at CT\&E and the resultant PDF qualities are outlined in Tables 3.2 and 3.3, and values for Buckskin PDF are shown for comparison. As can be seen from this information, the North Rochelle coal processed increased in heating value from $8,600 \mathrm{Btu} / \mathrm{lb}$ to over $11,300 \mathrm{Btu} / \mathrm{lb}$. The PDF produced was lower in quality than anticipated when the average coal reserve feedstock quality values are considered. This lower product quality may be explained, however, by examining the coal feedstock quality used for the ENCOAL plant test. The North Rochelle coal processed was higher in ash and therefore lower in Btu value than the composite average of the reserve. Therefore, the resultant PDF was also higher in ash and lower in Btu than anticipated. TEK-KOL believes that the PDF quality would have been enhanced if a representative sample of the total reserve coal was processed. However, by correlating between the coal quality processed and the actual average coal reserve quality, an $11,400 \mathrm{Btu} / \mathrm{lb}$, and a $6-8 \%$ ash PDF may be inferred. This corrected PDF quality is used as the basis for this study.

CDL quality is shown in Table 3.4. In general, the North Rochelle CDL exhibits characteristics very similar to Buckskin CDL which has proven to be a valuable fuel, and contains components with chemical feedstock potential. 


\section{Conclusions}

Evaluation of the testing data shows that, with the exceptions of lower moisture, sulfur, and ash contents, North Rochelle coal is quite similar to the Buckskin coal in meeting key criteria. Based on the similarity between the two coals and the success of the ENCOAL Plant in processing Buckskin coal, it can be concluded that:

- North Rochelle coal is a good candidate for upgrading using the LFC technology.

- There is a very high level of confidence regarding application of experience gained at the ENCOAL Plant to the processing of North Rochelle coal utilizing the LFC technology.

- The three-step process of evaluation to determine if a candidate coal is suitable for upgrading by the LFC process is effective.

Table 3.1: Technical Screening Criteria Comparison

\begin{tabular}{|c|c|c|c|c|c|c|}
\hline & $\begin{array}{l}\text { MoISTuRR } \\
\text { contrent } \\
(\mathrm{wt} \%)\end{array}$ & $\begin{array}{l}\text { AST } \\
\text { CONTENT } \\
(\% 1 \%)\end{array}$ & RATIO & $\begin{array}{l}\text { HiC } \\
\text { Mitar } \\
\text { RATIO? }\end{array}$ & $\begin{array}{l}\text { OAC } \\
\text { Molin } \\
\text { Ratrot }\end{array}$ & 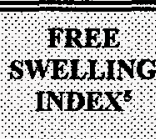 \\
\hline Technical Screening Criteria & $20-34$ & $\leq 5$ & $<1.4$ & $\geq 0.80$ & $\leq 0.20$ & $\leq 2$ \\
\hline $\begin{array}{l}\text { N. Rochelle Criteria Testing } \\
\text { Results }^{7}\end{array}$ & 25.9 & 4.7 & 1.17 & 0.81 & 0.20 & $<2$ \\
\hline $\begin{array}{l}\text { Buckskin Criteria Testing } \\
\text { Results }\end{array}$ & 29.1 & 5.3 & 1.14 & 0.83 & 0.18 & $<2$ \\
\hline ENCOAL Plant Data ${ }^{1}$ & 28.9 & 4.8 & 1.07 & 0.86 & 0.18 & NT \\
\hline
\end{tabular}

NOTES: 1) As-Received Test Data are for the period of 1/22/94 - 4/7/95.

2) Weight Ratio of Fixed Carbon to Volatile Matter (Ultimate Analysis)

3) Molar Ratio of Hydrogen to Total Carbon (Ultimate Analysis)

4) Molar Ratio of Oxygen to Total Carbon (Ultimate Analysis)

5) NT: Not Tested

6) NA: Not Available

7) Data are for $97 \%$ of Recoverable Reserves 
Table 3.2: Run of Mine Coal Qualities

\begin{tabular}{|c|c|c|}
\hline & (Average of 95 -May 97 ) & $\begin{array}{l}\text { North Rochelle } \\
\text { (November } 1995 \text { Test) }\end{array}$ \\
\hline \multicolumn{3}{|l|}{ Proximate } \\
\hline Moisture (wt\%) & 28.0 & 28.0 \\
\hline Ash (wt\%) & 5.5 & 5.6 \\
\hline Volatile (wt\%) & 32.0 & 31.0 \\
\hline Fixed Carbon (wt\%) & 34.5 & 35.4 \\
\hline \multicolumn{3}{|l|}{ Ultimate } \\
\hline Moisture (wt\%) & 28.0 & 28.0 \\
\hline Carbon (wt \%) & 49.5 & 49.2 \\
\hline Hydrogen $(w t \%)$ & 3.5 & 3.4 \\
\hline Nitrogen (wt\%) & 0.8 & 0.7 \\
\hline Sulfur (wt $\%)$ & 0.4 & 0.2 \\
\hline Ash (wt\%) & 5.5 & 5.6 \\
\hline Oxygen (wt \%) & 12.3 & 12.9 \\
\hline $\begin{array}{l}\text { Thermal Energy } \\
\text { Btu/lb (Kcal/kg) }\end{array}$ & $8,350(4,639)$ & $8,600(4,778)$ \\
\hline
\end{tabular}


Table 3,3: PDF Quality Comparison

\begin{tabular}{|c|c|c|}
\hline & (1995 Average) & $\begin{array}{l}\text { North Rochelle } \\
\text { (November } 1995 \text { Test) }\end{array}$ \\
\hline \multicolumn{3}{|l|}{ Proximate } \\
\hline Moisture (wt\%) & 8.90 & 8.10 \\
\hline $\operatorname{Ash}(w t \%)$ & 8.90 & 7.50 \\
\hline Volatile (wt \%) & 24.50 & 22.30 \\
\hline Fixed Carbon (wt $\%)$ & 57.34 & 61.80 \\
\hline Sulfur $(w t \%)$ & 0.36 & 0.30 \\
\hline $\begin{array}{l}\text { Thermal Energy } \\
\text { Btu/lb (Kcal/kg) }\end{array}$ & $11,100(19,980)$ & $11,300(20,340)$ \\
\hline Ash Mineral Analysis & Same as Coal & Same as Coal \\
\hline Ash Fusion Temperature & $2220^{\circ} \mathrm{F}\left(1216^{\circ} \mathrm{C}\right)$ & $2250^{\circ} \mathrm{F}\left(1232^{\circ} \mathrm{C}\right)$ \\
\hline Hardgrove Grindability Index & 47 & 46 \\
\hline
\end{tabular}

Table 3.4: CDL Quality Comparison

\begin{tabular}{|c|c|c|}
\hline & (1995 Average) & $\begin{array}{l}\text { North Rochelle } \\
\text { (November } 1995 \text { Test) }\end{array}$ \\
\hline API Gravity $\left({ }^{\circ}\right)$ & 2.3 & 3.0 \\
\hline$\%$ Sulfur & 0.6 & 0.3 \\
\hline$\%$ Nitrogen & 0.7 & 1.6 \\
\hline$\%$ Oxygen & 10.8 & 8.0 \\
\hline Viscosity @ $122^{\circ} \mathrm{F}$ or $50^{\circ} \mathrm{C} \mathrm{cSt}$ & 240 & 350 \\
\hline Pour Point ${ }^{\circ} \mathrm{F}\left({ }^{\circ} \mathrm{C}\right)$ & $80(27)$ & $75(24)$ \\
\hline Flash Point ${ }^{\circ} \mathrm{F}\left({ }^{\circ} \mathrm{C}\right)$ & $218(103)$ & $220(104)$ \\
\hline Heating Value: Mbtu/gal (Kcal/kg) & $140(2051)$ & $138(2022)$ \\
\hline$\%$ Water & 0.6 & 0.5 \\
\hline$\%$ Solids & $2-4$ & 3.8 \\
\hline$\%$ Ash & $0.2-0.4$ & 0.6 \\
\hline
\end{tabular}




\section{Section 4.0 Market Assessment of PDF and CDL}

\section{Introduction}

The LFC Process is unique compared to other low-rank coal upgrading processes in that it produces two marketable products, PDF and CDL. PDF and CDL are truly coproducts because the viability of a future commercial LFC plant will depend on getting substantial revenue from each product stream. Recent marketing efforts have focused on identifying and developing the highest value markets for each product. Results of these efforts made it possible to estimate that existing market prices will net back revenues in the range of $\$ 18$ to $\$ 20$ per ton and barrel for PDF and CDL respectively.

\section{Summary}

PDF can compete in two domestic U.S. markets: the electric utility market and the noncoking coal metallurgical market. The electric utility industry offers the opportunity to participate in a large volume but strongly price-competitive market. TEK-KOL, through studies completed by Resource Data International (RDI), estimates that market volume for PDF will total 78 million tons/year by 2000 and will increase to 148 million tons/year by 2005 .

The application of PDF to noncoking metallurgical coal applications shows great promise for increasing net back values. PDF offers a very competitive alternative for pulverized coal injection and, because of its high fixed carbon content, has competitive advantage in direct iron reduction processes.

Based on available markets and pricing, TEK-KOL marketers project that $80 \%$ of the PDF production from a three-module LFC Commercial plant could be sold into the utility market, and the remaining $20 \%$ can be moved into the metallurgical market.

CDL from the ENCOAL Plant has been sold to date in the residual fuel oil market as an industrial boiler fuel, but has more potential when fractionated into four separate products. Considerable work has been completed in determining CDL's composition, and value-added markets have been identified for potential CDL-derived products. A process has been developed to separate CDL into four component fractions:

- crude cresylic acid,

- petroleum refinery feedstock, similar to a petroleum gas oil,

- $\quad$ oxygenated middle distillate usable as an industrial fuel, and

- $\quad$ pitch suitable for blend stock into anode binder products.

Each of these markets is well defined, and discussions with potential customers have proven the viability of these CDL -derived products. 


\section{Data \\ PDF Markets}

The U.S. electric utility market is clearly the largest market for PDF, but a relatively small but growing market for noncoking metallurgical coals appears to provide the best opportunity for higher net back values for PDF. Both of these markets are discussed in further detail in the following sections.

In general, however, the wide acceptance of PDF into the broad utility, metallurgical, or industrial marketplace depends on PDF's meeting three important product handling and utilization criteria:

1. The potential for PDF to self-ignite must be equal to or less than the potential for the parent coal to self-ignite.

2. The dustiness of PDF must be less than the dustiness of Powder River Basin coal.

3. PDF flame stability and other combustion characteristics must remain constant as the volatile content of PDF is reduced.

Laboratory combustion tests and large-scale commercial test burns have demonstrated that PDF meets all three criteria. It has been proven that PDF will burn very well, and that PDF is anywhere from less dusty than, to as dusty as run-of-mine (ROM) Powder River Basin coal. ENCOAL has also shown that it can produce stable PDF through a ground-spreading technique, and commercial shipments of PDF stabilized using that method showed no tendency toward self-heating. A faster mechanical stabilization process has recently been proven in trials run at the ENCOAL Plant, and a commercial-sized version is incorporated into the design of the LFC Commercial Plant.

Detailed descriptions of laboratory combustion tests and commercial test burn results are incorporated in other reports published by the DOE. ${ }^{[1][2][3]}$

\section{U.S. Utility Markets Overview}

To better define the potential market for PDF, Resource Data International (RDI) was engaged to perform a competitive market study. That study, completed September 8, 1995, addressed the U.S. utility market in detail and arrived at a number of significant conclusions:

1. Fifty-three power plants operated by 34 utilities were identified as the "best potential" market for PDF on the basis of meeting the following criteria:

- These utilities had boilers requiring low-ash fusion coal (primarily cyclone and wet bottom boilers). 
- The boilers required high-Btu fuel.

- The utilities wanted to switch to low-sulfur coal to meet Phase I and Phase II CAAA compliance levels.

- Transportation economics were favorable.

These 53 plants represent a potential annual market of 65 million tons by the year 2000 and 81 million tons by the year 2005 .

2. Additionally, 37 power plants were identified as a "challenging" market for PDF because they burn coal with different specifications than those of PDF. Given price incentives and PDF 's other advantages, however, the utilities may adopt PDF as a fuel. Appropriate strategies will target this huge potential market: these 37 plants represent a 13 million-ton/year market by the year 2000 and 67 million tons/year by the year 2005 .

The expected net back value of PDF into the "best potential" and "challenging" markets is estimated to be in the $\$ 18$ to $\$ 20$ per ton range (in constant 1996 dollars for an $11,400 \mathrm{Btu} / \mathrm{lb}$ product) for the great majority of the utilities analyzed. The PDF net back values estimated by RDI were based upon evaluating PDF against the most competitive high-Btu coal source to a specific power plant, which were generally coals form the Uinta Basin of Colorado and the Green River and Hams Fork Basins of Wyoming; to a lesser extent, low-fusion Pocahontas \#3 coal and other Eastern bituminous coals.

A number of factors could have a significant positive impact on the size and value of the utility market for PDF. These factors, some of which were touched on in the RDI study, are discussed below and were not reflected in the utility market revenue estimates used for this project economics.

\section{Positive PDF Burning Characteristics - $\mathrm{NO}_{\mathrm{x}}$ Emission Reduction}

Recent research indicates an important environmental advantage that PDF could bring to the utility market: laboratory and test burn data suggest that combustion of PDF could result in lower $\mathrm{NO}_{\mathrm{x}}$ emissions than would result from the combustion of other bituminous coals.

A laboratory combustion test of PDF and an Australian bituminous coal performed by Electric Power Development Company (EPDC) in Japan in 1994 appeared to indicate $\mathrm{NO}_{\mathrm{x}}$ emissions levels that were roughly proportional to the nitrogen contained in the coal. PDF, which had $40 \%$ less nitrogen than the Australian coal, produced $40 \%$ lower $\mathrm{NO}_{\mathrm{x}}$ emissions. Another significant finding of this laboratory combustion work was that the same percent reduction of $\mathrm{NO}_{\mathrm{x}}$ emissions was maintained as the amount of overfired air was increased. (The use of overfired air is a $\mathrm{NO}_{\mathrm{x}}$ reduction technique). Additionally, while increasing the amount of overfired air typically results in less complete combustion of the coal (as evidenced by the higher percentage of unburned carbon in the ash of the Australian 
coal), there was only a very minor increase in unburned carbon in the PDF ash at high levels of overfired air.

A 1995 test burn of PDF at Muscatine Power \& Light's Unit 8 indicated $\mathrm{NO}_{\mathrm{x}}$ emission levels for PDF /Powder River Basin blends equal to or less than straight-run Powder River Basin coal, and a 1996 test burn at Indiana-Kentucky Electric Cooperative's Clifty Creek Station demonstrated $\mathrm{NO}_{\mathrm{x}}$ reduction in what may represent the most significant test to date. At this utility, PDF was blended with Ohio high-sulfur coal and burned in the Babcock \& Wilcox open-path, slag-tap boiler with full instrumentation. In addition to increasing the unit's capacity relative to the base blend, burning the PDF blend resulted in at least a $20 \% \mathrm{NO}_{\mathrm{x}}$ reduction. A third party analysis confirmed these results. ${ }^{[3]}$

Conventional wisdom would expect PDF to produce higher flame $\mathrm{NO}_{\mathrm{x}}$ emissions than Powder River Basin coal because PDF burns at higher flame temperatures than Powder River Basin coal, and higher flame temperatures generally produce higher $\mathrm{NO}_{\mathrm{x}}$ emissions. However, observation and data from test burns and the Shell Development Company laboratory show increases in flame stability. A more stable flame produces uniform temperatures and reduces localized "hot spots," possibly contributing to reduced overall flame $\mathrm{NO}_{\mathrm{x}}$ generation.

These data are not conclusive, but are indicative of PDF's potential to reduce $\mathrm{NO}_{\mathrm{x}}$ emissions. Many factors beyond the nitrogen content of the coal may impact $\mathrm{NO}_{\mathrm{x}}$ generation in a boiler, including boiler type and size, boiler load, burner design and flame characteristics of coal. However, combustion of PDF/coal blends in a low-NO $\mathrm{NO}_{\mathrm{x}}$ burner at Black Hills Power in December 1996 still showed no increase in $\mathrm{NO}_{x}$ production, so additional full-scale test burns of PDF in utility boilers will be required to more definitively assess PDF's potential in reducing $\mathrm{NO}_{\mathrm{x}}$ emissions.

The potential economic impact of Title IV of the 1990 Clean Air Act Amendments (CAAA) on the utility industry is enormous, and PDF, a fuel that can help reduce $\mathrm{NO}_{\mathrm{x}}$ emissions, may become a major preferred fuel source. While regulations under Title I of the CAAA, which have been finalized, are less severe than the regulations expected under Title IV, some plants may have trouble meeting Title I compliance with simple burner technology. These plants could present marketing opportunities for PDF. No attempt was made to quantify the positive impact on expected PDF net back values resulting from the utility industry placing a value on a fuel that could reduce $\mathrm{NO}_{\mathrm{x}}$ emissions.

As environmental regulations become stricter, especially those regarding $\mathrm{NO}_{\mathrm{x}}$, the desirability of PDF may increase. In fact, the potential for reduced $\mathrm{NO}_{\mathrm{x}}$ emissions increases the likelihood that PDF will become a preferred fuel in all utility markets. 


\section{Metallurgical Market Opportunity}

The markets for PDF have opened up for metallurgical use in the steel industry, where a demand for coke substitutes is building up world wide. In steel making, in addition to the usual drive for higher efficiencies, environmental constraints on coke production and the lower limits on permissible stack emissions are strongly motivating development of new technologies. Techniques to replace coke in the blast furnace, new iron ore reduction techniques and new steel making technologies have emerged to replace the traditional blast furnaces and coke oven batteries.

Coke in the blast furnace has three main functions: as a reductant, a heat source, and as a porous structure to support the burden inside the blast furnace. Pulverized coal injection (PCI) and granular coal injection (GCI) are techniques that replace the coking coal in the blast furnace. Either method can only assume the coke's roles as reductant and heat source, so injection rates are limited by the remaining need for coke to provide the porosity and support the burden. Regardless of this limitation and the concurrent increases in the efficiency of coke production and blast furnace operation, PCI injection rates of $250 \mathrm{Kg} /$ ton-hot-metal $(\mathrm{thm})$ have been realized on blast furnaces with coke rates between $200-250 \mathrm{Kg} / \mathrm{thm}$. PDF's characteristics make it an ideal replacement for the coke and limited testing has been conducted utilizing CDL as a blast furnace injectant. The reduction in coke production also provides an additional market for CDL as a replacement for coal tars produced during the coking process.

Another answer to the decline of coke production lies in direct reduction techniques, some of which are already commercial, and other technologies, using direct smelting techniques, have passed the pilot plant stages. Both offer opportunities for PDF marketing. These emerging technologies, which include COREX, HIsmelt, AISI direct steel making, Fastmet, the DIOS process, and the Romelt process are coal-based methods to produce clean iron units. For these new technologies a different set of coal requirements have emerged, centered on the volatile content and the elemental structure of coal. The new criteria do not require strength, but favor low to medium volatile content, low sulfur, and low atomic ratios of oxygen, hydrogen, and carbon. The LFC process removes volatiles, sulfur, hydrogen, and oxygen from coal and enhances carbon content of the solid product. Therefore, the coal properties that are important for the production of direct reduced iron (DRI), specifically a high fixed carbon content, a low sulfur content, and a high reactivity, make PDF attractive as a reductant for the conversion of iron ore to DRI.

Three tests were performed in the United States and Japan to assess the acceptability of PDF in the metallurgical markets. For simplicity the results of these tests will be explained briefly:

1. Petrographic studies were performed by both Mitsui Mining Company and Coal Petrographic Associates. Both studies determined the reflectivity of PDF to be 1.3, a value that is typical of bituminous coals. Typical reflectivity of subbituminous coal is 0.5 to 0.6 . This is evidence that the LFC process transforms some of the characteristics of subbituminous coal into those of bituminous coal, and the PDF displays positive characteristics of both subbituminous and bituminous coals. 
2. A grinding test was performed by Williams Patent Crusher and Pulverizer Company. Results indicate mill performance with PDF increased by over 60\% (under two separate operating conditions) compared to Appalachian high volatile coal that is used for the comparative standard.

3. Flowability tests performed by Jenike and Johanson indicated that PDF is suitable for dense phase pneumatic conveying and does not have cohesive, compressibility or permeability characteristics that would require special equipment for pneumatic conveying.

Further research into uses of PDF in metallurgical markets is ongoing. In 1996, a contract was issued to test PDF in DRI production. The DRI has been processed and analyzed, showing that they achieved $96 \%$ metallization and contained 0.08 to $0.15 \%$ sulfur. These results confirm that PDF can be used as a good reductant for DRI. ENCOAL is proceeding with the next step of testing to determine the feasibility of utilizing PDF as the reductant for a targeted iron ore and DRI process.

Beyond the testing that ENCOAL has contracted to determine the acceptability of PDF in the metallurgical market, companies in Japan and Austria have also conducted testing that indicate PDF displays a high degree of thermal stability and is acceptable as a slurried feedstock for coal gasification.

Table 4.1 is a summary of the North American blast furnaces with existing and planned PCI/GCI systems. Currently this market amounts to approximately 4 million tons/year and will grow as the planned projects materialize. To date, discussions with PCI customers have been concentrated with those with installations in Northern Indiana, along Lake Michigan, because those plants have the most favorable logistics for PDF originating in Wyoming. In particular, assessment of competing Eastern bituminous coals has indicated that net backs in the range of $\$ 26$ to $\$ 30$ per ton for PDF product are attainable. Twenty percent of the production of a three-module LFC plant is reflected in the economics of this study using this price range.

\section{Transportation Issues}

The most significant transportation issue that would affect the marketing of PDF is creating access to more than one railroad. For this Commercial Plant Study, this issue is solved by the plant siting choice. The chosen commercial plant site provides access to both the Burlington Northern Santa Fe, and the Union Pacific railroads. Access to two railroads assures access to the most competitive transportation rates out of the Powder River Basin. 
Table 4.1:

Existing North American PCI/GCI Blast Furnaces (December 1996)

\begin{tabular}{|c|c|c|c|c|}
\hline \multirow{2}{*}{ Company and Plant Location } & \multirow{2}{*}{$\begin{array}{l}\text { Operation } \\
\text { Start Date }\end{array}$} & \multirow{2}{*}{$\begin{array}{l}\text { Capacity } \\
\text { (thm/day) }\end{array}$} & \multicolumn{2}{|c|}{ Annual Coal Needs (Mtpy) } \\
\hline & & & (a) $200 \mathrm{lb} / \mathrm{hm}$. & (a) 400 lb/thm \\
\hline $\begin{array}{l}\text { Bethlehem Steel } \\
\text { Burns Harbor, IN }\end{array}$ & 1995 & $2 \times 7000$ & 490 & 980 \\
\hline $\begin{array}{l}\text { U.S. Steel } \\
\text { Gary, IN }\end{array}$ & 1993 & $\begin{array}{l}3 \times 2700 \\
1 \times 9000\end{array}$ & 595 & 1190 \\
\hline $\begin{array}{l}\text { Inland Steel } \\
\text { Indiana Harbor, } \mathbb{N}\end{array}$ & 1993 & $\begin{array}{c}1 \times 2500 \\
1 \times 3000 \\
1 \times 10000\end{array}$ & 543 & 1085 \\
\hline $\begin{array}{l}\text { Armco Steel } \\
\text { Ashland, KY }\end{array}$ & 1973 & $1 \times 3500$ & 123 & 245 \\
\hline $\begin{array}{l}\text { USS/Kobe } \\
\text { Lorain, OH }\end{array}$ & 1994 & $2 \times 3800$ & 266 & 532 \\
\hline $\begin{array}{l}\text { Stelco } \\
\quad \text { Hamilton, Ont }\end{array}$ & 1996 & $2 \times 7000$ & 490 & 980 \\
\hline $\begin{array}{c}\text { National Steel } \\
\text { Detroit, MI }\end{array}$ & $\begin{array}{l}\text { late } \\
1996\end{array}$ & $1 \times 7000$ & 245 & 490 \\
\hline
\end{tabular}

\section{Markets}

When the ENCOAL LFC Plant was designed and built, it was envisioned that crude CDL could be readily sold into the industrial residual fuel oil market or be sold as a chemical feedstock. Because of these expectations, and to keep the ENCOAL Plant simple, the facilities for upgrading CDL were not incorporated into the ENCOAL Plant design.

The industrial residual fuel oil market has not delivered the expected opportunity for CDL. Instead, the four CDL-derived products have been found to offer the most substantial market possibilities, and both the three-module and the single-module commercial plants described in this Study incorporate some simple processes to produce four marketable product streams from CDL. Other markets for crude CDL, such as the refinery feedstock market, could be developed, but are not likely to produce net backs as high as those from the four distillation products. 
Most of the physical characteristics of CDL such as pour point, heating value, flash point, viscosity, and API gravity are in the range of acceptability for many residual oil markets. Table 4.2 compares North Rochelle Mine CDL specifications with typical $\# 6$ oil specifications. The low sulfur content of CDL makes it desirable in blends with high-sulfur residual fuels that are more prevalent (and carry a lower value in the market place). The two major impediments to CDL gaining wide acceptability as an industrial boiler fuel are its odor and its lack of compatibility when blended with the most readily available residual fuel oils.

Other markets for crude CDL that are currently being investigated include petroleum refinery feed stock, marine transportation, and coal tar replacement.

Table 4.2: Typical CDL Quality

\begin{tabular}{|c|c|c|}
\hline & North Rochelle CDI & $\begin{array}{l}\text { Low Sulfur } \\
\text { No. } 6 \text { OHI }\end{array}$ \\
\hline Gravity ( ${ }^{\circ}$ API) & 3.0 & 5.0 \\
\hline Sulfur (wt \%) & 0.3 & 0.8 \\
\hline Nitrogen (wt \%) & 1.6 & 0.3 \\
\hline Oxygen (wt \%) & 8.0 & 0.6 \\
\hline $\begin{array}{l}\text { Viscosity @ } 122^{\circ} \mathrm{F} \text { or } 50^{\circ} \mathrm{C} \\
\text { (cSt) }\end{array}$ & 350 & 420 \\
\hline Pour Point ${ }^{\circ} \mathrm{F}\left({ }^{\circ} \mathrm{C}\right)$ & $77(25)$ & $50(10)$ \\
\hline Flash Point ${ }^{\circ} \mathrm{F}\left({ }^{\circ} \mathrm{C}\right)$ & $220(104)$ & $150(66)$ \\
\hline Mbtu/gal (Kcal/kg) & $138(2022)$ & $150(2198)$ \\
\hline
\end{tabular}

\section{Upgrading}

In the summer of 1995 , Dakota Gasification Company was engaged to perform a laboratory investigation of the composition of the crude CDL produced by ENCOAL. That study indicated the presence of many high value chemical constituents in CDL that are potentially extractable. On the basis of that study, M.W. Kellogg was engaged to design a process to separate crude CDL into four intermediate products that would be useful feedstocks for various chemical and refining processes:

1. Crude cresylic acid - suitable for shipment to cresylic acid refiners for separation into phenol, cresols and xylenols. The production from the Commercial plant is anticipated to be approximately $50 \%$ cresylics and $50 \%$ neutral oils. Based upon 
discussions with the leading North American manufacturer of cresylic acid products, the delivered value of the cresylic acid portion has been estimated at $\$ 66.62 / \mathrm{bbl}$. The delivered value of the neutral oils has been conservatively estimated at $\$ 16.00 / \mathrm{bbl}$. Calculating the weight averaged delivered value and subtracting out the cost of caustic extraction and transportation gives a net back value in the range of $\$ 19$ to $\$ 21$ per barrel for the crude cresylic CDL product.

2. Pitch - usable as a binder in anode manufacturing. Other uses include roofing pitches and road sealants. According to discussions with anode pitch manufacturers, CDL pitch product is not suitable on its own without blending. CDL pitch has been tested by several pitch manufacturers and delivered value estimates of $\$ 42.00$ to $\$ 51.55 / \mathrm{bbl}$ have been obtained. For the purposes of this Study, the lower value minus transportation cost has been used.

3. Refinery Feedstock (low oxygen middle distillate) - a satisfactory replacement gas oil feed to catalytic cracking units in petroleum refineries, resulting in the production of transportation fuels. Discussions with several Wyoming region refining companies have resulted in an estimated product value of $\$ 16.00 / \mathrm{bbl}$ delivered to Billings, MT.

4. Oxygenated Middle Distillate - planned to be used as an industrial fuel. Several companies have expressed interest in this fraction due to its high catechol content; however, detailed assessment is currently being examined. For the purposes of this Study, a conservative net back value of $\$ 5.50 / \mathrm{bbl}$ has been assumed for this product.

The crude cresylic acid and the pitch represent important new raw material sources for their respective industries because of the decline of traditional feedstock sources derived from coke oven liquids, in turn resulting from the reduction in metallurgical coke capacity and production.

\section{Conclusions}

Based upon market research studies, TEK-KOL believes that $80 \%$ of the PDF production from a three-module LFC Commercial plant could be sold into the utility market. The opportunity represented by PDF metallurgical markets represents at least $20 \%$ of the plant capacity. For the purposes of this study, average PDF net-back revenues in the range of $\$ 18$ to $\$ 20$ per ton were used.

CDL continues to be of interest in the fuel oil markets, but a far more attractive option is to separate it into the four higher value products outlined above on $10 \%, 30 \%, 35 \%$, and $25 \%$ ratios respectively. Well-defined markets exist for each of the above products, and discussions continue with potential customers have indicated that the CDL fractions may be suitable for their needs. The weight averaged net back value of CDL utilized for this Study is in the $\$ 18$ to $\$ 20$ per barrel range. 
Section 5.0 Engineering

5.1 Introduction and Overview

\section{Summary}

The LFC Commercial Plant design is based on three major components: design information from the ENCOAL project, the ENCOAL Plant's most recent data and operating results, and test runs of coal from the North Rochelle Mine as discussed in Section 3.0. The North Rochelle Mine, the prospective mine site, is about 15 miles southeast of Wright, Wyoming, or 60 miles southeast of the existing ENCOAL plant.

The engineering work for this Phase II Study was performed by TEK-KOL or Mitsubishi Heavy Industries through agreements with the TEK-KOL Partnership. The first step in engineering was to prepare a document that would make it possible to estimate costs. This design basis document covers the geological, geotechnical, climatological, capacity, engineering and utility requirements for the LFC Commercial Plant project. It also establishes the codes and standards that will be followed and sets forth the underlying assumptions and process performance.

\section{Introduction}

As it exists today, the LFC Technology is well developed and demonstrated through the joint efforts of the TEK-KOL partners, SGI International and Bluegrass Coal Development Company. Benchscale and pilot-plant testing of the LFC Process began in the early 1980's. By 1987, when ENCOAL's then-parent Shell Mining Company became involved, SGI had worked with three successively larger process demonstration units (PDU)s at three different equipment manufacturers' research and development facilities. The TEK-KOL Partnership was formed in mid-1987, and SGI and Shell Mining Company continued process testing and development at Salem Furnace Company where the latest PDU was in operation.

In 1987 and 1988, the Salem PDU was used to perform a substantial amount of pilot-plant testing of the LFC Process and laboratory testing of PDF and CDL. It was at the Salem PDU that the process evolved from a batch to a semi-continuous operation, and several alternative liquid recovery schemes were tested. The pilot-plant tests showed that the process was viable, predictable and controllable and could produce PDF and CDL to desired specifications. Based on the success of the PDU testing and product market assessments, Shell Mining Company decided to proceed with the 1,000-ton/day ENCOAL Plant.

Not a pilot plant or a "throw-away," the ENCOAL Plant was designed to commercial standards and is intended to operate for at least 10 years. The Plant, designed, constructed and operated in cooperation with the U.S. Department of Energy, uses commercially available equipment as much as possible, and state-of-the-art computer control systems. Best available control technology for all environmental controls minimizes releases, and a simplified flowsheet makes two products matched to existing markets. The intent in designing the Plant was to demonstrate the core process without making the project overly complicated or expensive. 
Operation of the ENCOAL Plant over the last $4 \frac{1}{2}$ years revealed that numerous equipment and process modifications were necessary to produce PDF and CDL efficiently, continuously and within specifications. Most of the early changes were related to equipment reliability, plant availability, plant operability and maintenance. By 1993, as the Plant was operated for extended periods, process shortcomings appeared. Deactivation of PDF was not possible in the original plant configuration, and an additional processing loop was added. In 1994-95, combustor controls were changed, and a process water clean-up system and an oily solids disposal facility were added ${ }^{[4]}$

Most recently, the testing of a PDF finishing step was completed. This testing successfully demonstrated that stabilized PDF can be made continuously in commercially available equipment, and this equipment will be added to the ENCOAL Plant in 1997. This valuable information and experience has been incorporated into the design of the LFC Commercial Plant.

\section{Process Description}

Figure 5.1.1 is a simplified flow diagram of ENCOAL's application of the LFC Technology. The process involves heating coal under carefully controlled conditions. Nominal 3- by 0 -inch ROM coal is conveyed from the Buckskin Mine to a storage silo. The coal from this silo is screened to remove oversize and undersize materials. The $2 \times 1 / 8$ inch coal is fed into a rotary grate dryer where it is heated by a hot gas stream. The residence time and temperature of the inlet gas have been selected to reduce the moisture content of the coal without initiating chemical changes. The solid bulk temperature is controlled so that no significant amounts of methane, carbon monoxide or carbon dioxide are released from the coal.

Figure 5.1.1: ENCOAL Plant Simplified Process Flow Diagram

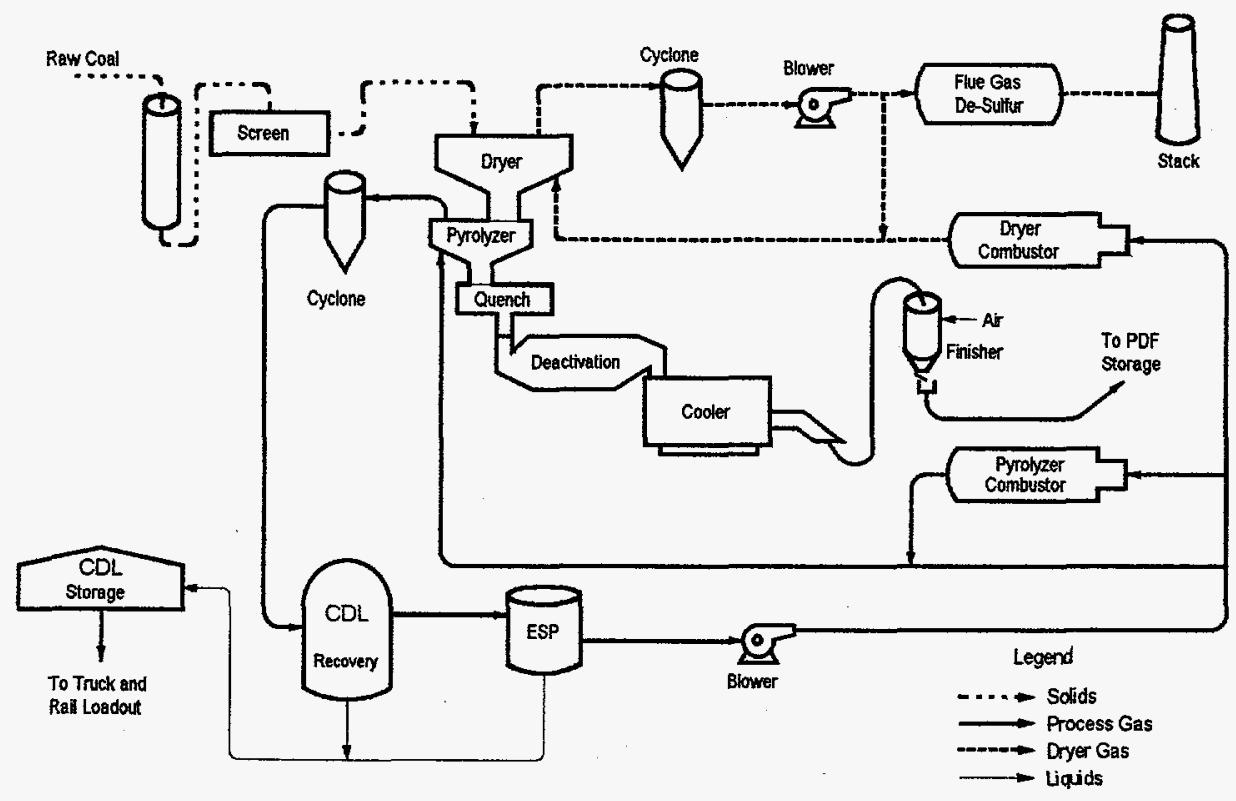


The solids from the dryer are then fed to the pyrolyzer; there a hot recycle gas stream increases the temperature to about $1,000^{\circ} \mathrm{F}$ on another rotary grate. The rate of heating and the residence time of the solids are carefully controlled because these parameters affect the properties of both solid and liquid products. During processing in the pyrolyzer, all remaining water is removed, and a chemical reaction occurs, releasing volatile gaseous material. Solids exiting the pyrolyzer are quickly quenched to stop the pyrolysis reaction, then transferred to a small surge bin in the vibrating fluidized bed (VFB) deactivation loop shown in Figure 5.1.2.

In the VFB loop, the partially cooled, pyrolyzed solids contact a gas stream containing a controlled amount of oxygen. A reaction, termed oxidative deactivation, occurs at active surface sites in the particles, reducing the tendency to spontaneously ignite. The heat generated by this reaction is absorbed by the fluidizing gas stream. This gas stream then circulates through a cyclone, which removes entrained solids, passes through a heat exchanger and is returned by a blower to the VFB. Oxygen content in the loop is maintained by introducing the proper amount of air through a control valve. Excess gas in the loop is purged to the dryer combustor for incineration.

Following the VFB, the solids are cooled to near atmospheric temperature in an indirect rotary cooler. A controlled amount of water is added in the rotary cooler to rehydrate the PDF to near its ASTM equilibrium moisture content. This is also an important step in the stabilization of the PDF. Additional contact with oxygen at fairly low temperatures is the final step in stabilization, and a finishing step at this point in the process will be added as shown in Figure 5.1.3. The cooled PDF is then transferred to a storage bin. Because the solids have little or no free surface moisture and are likely to be dusty, a patented dust suppressant is added as PDF leaves the product surge bin. Patents have been issued on both the deactivation and rehydration steps.

Figure 5.1.2: PDF Deactivation (VFB) Loop Simplified Flow Diagram

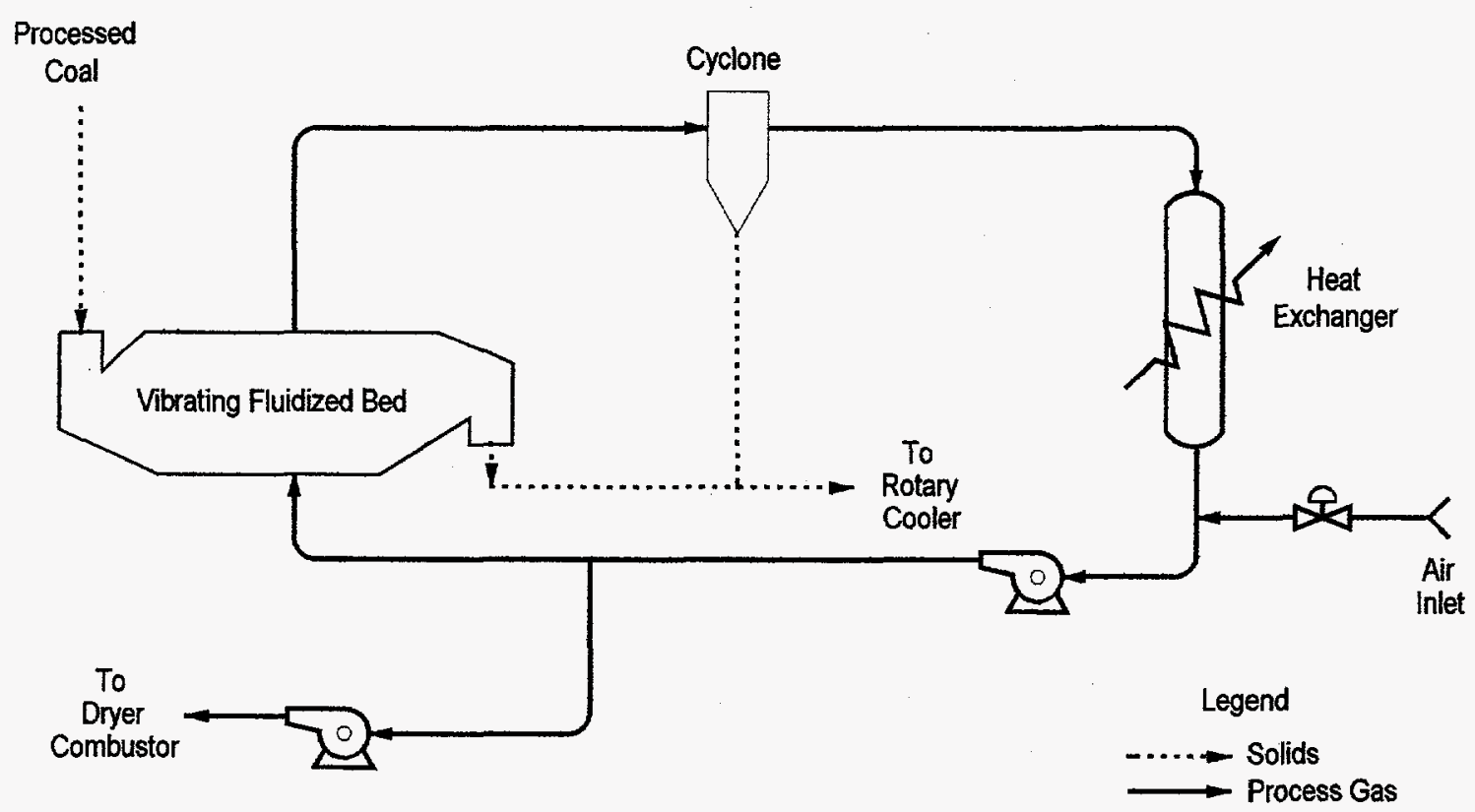


Figure 5.1.3: PDF Finishing Loop Simplified Process Flow Diagram

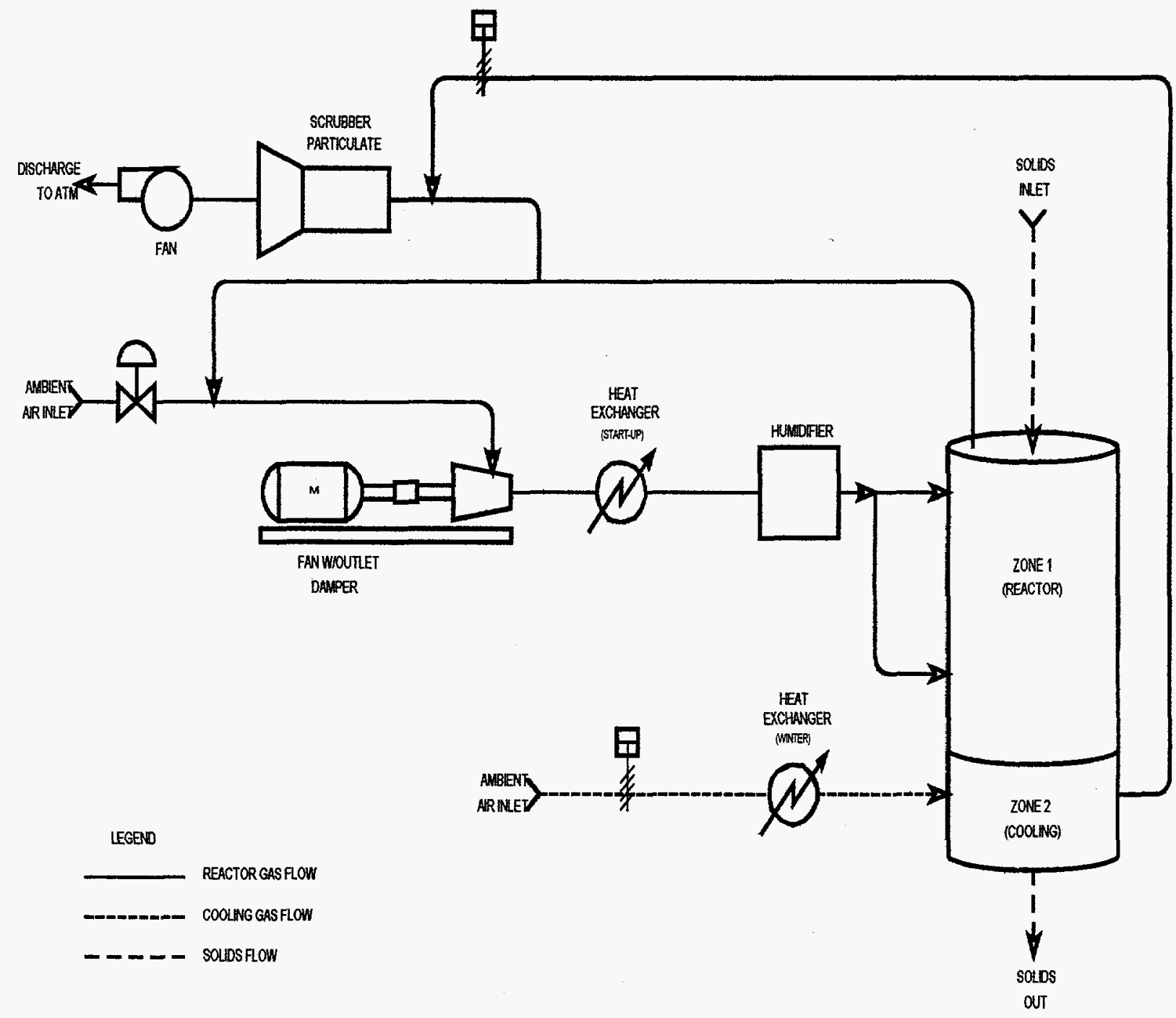


The hot gas produced in the pyrolyzer is sent through a cyclone for particulate removal. The gas is then cooled in a quench column to stop any additional pyrolysis reactions and to condense the desired liquids. Only the CDL is condensed in this step; the condensation of water is avoided. Electrostatic precipitators recover any remaining liquid droplets and mists from the gas leaving the condensation unit.

Almost half the residual gas from the liquid recovery unit is recycled directly to the pyrolyzer. Some of the remainder is burned in the pyrolyzer combustor and then blended with the recycled gas to provide heat for the mild gasification reaction. The remaining gas is burned in the dryer combustor, converting sulfur compounds to sulfur oxides. Nitrogen oxide emissions are controlled through appropriate combustor design. The hot flue gas from the dryer combustor is blended with the recycled gas from the dryer to provide the heat and gas flow necessary for drying.

The unrecycled portion of off-gas from the dryer is treated in a wet gas scrubber and a horizontal scrubber, which use water-based sodium carbonate solutions. The wet gas scrubber recovers the fine particulates that escape the dryer cyclone, and the horizontal scrubber removes most of the sulfur oxides from the flue gas. The treated gas is vented to a stack, and the spent solution is discharged into a pond for evaporation. The Plant has several utility systems supporting its operation, including nitrogen, steam, natural gas, compressed air, bulk sodium carbonate and glycol/water heating and cooling systems.

Figure 5.1.4 is an overall concept diagram for the full-scale, three-unit LFC Commercial Plant. CDL upgrading, raw coal storage, PDF storage and flue gas scrubber system are common to all three LFC units. A cogeneration power plant, operated by a third party, is also sited adjacent to the commercial plant. Run-of-mine $2 \times 0$ inch coal from the mine is transferred to each unit by a transfer tower with a sampler and taken to a large slot storage barn. A single conveyor feeds each LFC unit.

After processing, the PDF from each unit is transferred to a single conveyor that elevates the PDF to a large storage barn. When a customer's unit train arrives, the PDF is loaded into rail cars by an automated batch weigh system, and a chemical car topper is applied to reduce product losses during shipment. CDL from each unit is combined and sent through a CDL solids removal system prior to being piped to the CDL upgrading unit. Here the $\mathrm{CDL}$ is converted to four products by distillation and solvent extraction: a crude cresylic acid, pitch, a refinery feedstock and an oxygenated middle distillate.

The fines removed in the drying and pyrolysis steps in each LFC unit serve as a supplementary fuel for a cogeneration boiler. The fines are conveyed in an inerted pneumatic system to the boiler, where they are blended with ROM coal and burned along with dirty gases from the PDF quench system and deactivation loop. A flue gas clean-up system is provided for both a cogeneration boiler and dryer off-gas as shown. 
Figure 5.1.4: Commercial Plant Concept Diagram

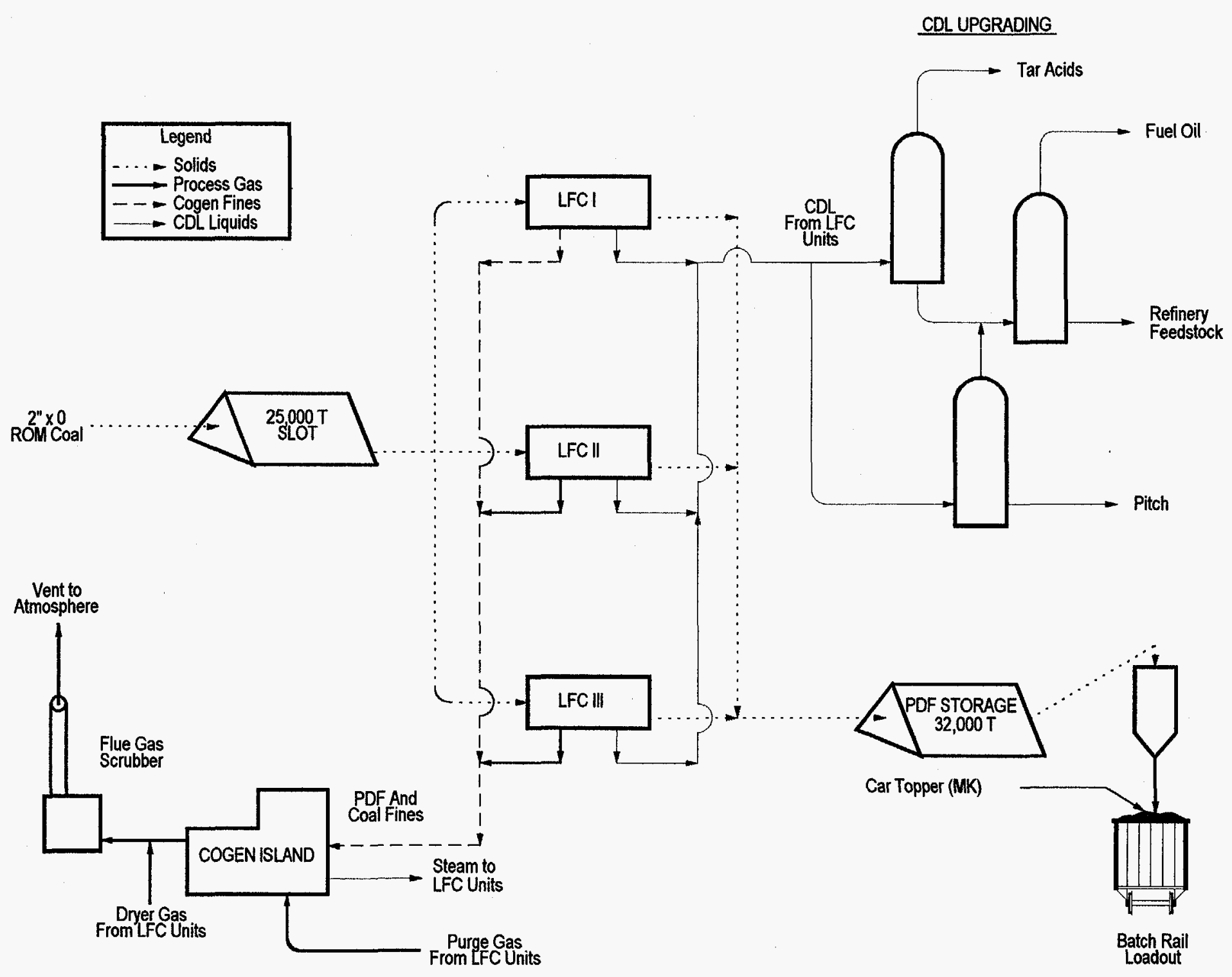




\section{Intellectual Property}

TEK-KOL's assets are inextricably tied to the LFC technology and as such, protection of these assets is paramount. Since the original U.S. patent number 4,395,309 on the overall LFC Process was issued to Dr. Ernest Esztergar in 1984, there have been many improvements and additional discoveries. To solidify TEK-KOL's intellectual property position, nine additional patents have been issued or filed, including an updated version of the overall LFC patent.

In addition to the patentable discoveries, a significant amount of "know-how" and proprietary information is involved in the LFC Control System. Computer code, mathematical algorithms and plant operating data comprise a large body of intellectual property that is protected by maintaining confidential information filing, labeling and distribution controls. Table 5.1.1 illustrates the current status of the TEK-KOL intellectual property.

\section{Conclusion}

The following sections describe the engineering work that was performed to scale the ENCOAL Plant up from 1,000 tons/day to a full commercial-size plant with three 5,000-metric ton/day parallel units. The design basis document and information from the material balance were used to develop the design for the commercial plant. MHI engineering developed the design and costs for the LFC modules, and TEK-KOL staff worked up the off-sites, selected major equipment, determined permitting requirements and cogeneration/scrubber design and costs.

Unlike the ENCOAL Plant, the commercial design is based on an MHI combined dryer/pyrolyzer grate design that has been used for quenching coke. Some questions remain on the application of this grate to the LFC Process, but these questions will be answered by modeling and testing in the near future. The cost benefits of using the combined grate design are quite significant. Other differences between the ENCOAL Plant and the commercial design are discussed in later sections.

The transition from the Salem PDU to the ENCOAL Plant was from 200 pounds/hour to 1,000 tons/day. The scale-up to the Commercial Plant is much smaller, and entails much less risk. Risk has also been significantly reduced through hands-on experience with commercial-size equipment and the solution of the process challenges identified during the demonstration phase of the project. In addition, more than 3,000 tons of North Rochelle coal have been processed in the ENCOAL Plant, and no problems have been identified. The plant performance and product recoveries used in this Phase II Study are based on the results of this coal test run, and are tempered by ENCOAL's experience with the Plant over the past few years. 
Table 5.1.1: TEK-KOL Intellectual Property Status (as of 3/12/97)

\begin{tabular}{|c|c|c|c|c|c|c|c|}
\hline No & Subject of Invention & Inventors & $\begin{array}{l}\text { Responsible } \\
\text { Person }\end{array}$ & flungloats & $\begin{array}{l}\text { Extinated } \\
\text { Bar Date }\end{array}$ & Patent alty & \\
\hline 1 & $\begin{array}{l}\text { U.S. Patent } \# 5,401,364 \text { a } \\
\text { process for treating noncaking, } \\
\text { noncoking coal to form char } \\
\text { with process derived gaseous } \\
\text { fuel having a variably } \\
\text { controllable calorific heating } \\
\text { value. }\end{array}$ & F. Rinker & F. Rinker & $\begin{array}{l}\text { Filed 3/11/93 } \\
\text { Name Change } \\
\text { CIP 7/94 }\end{array}$ & April 1994 & $\begin{array}{l}\text { Larry } \\
\text { Meenan } \\
\text { Toledo, OH }\end{array}$ & $\begin{array}{l}\text { Issue Date: } \\
\text { March 28, } 1995\end{array}$ \\
\hline 2 & $\begin{array}{l}\text { U.S. Patent } \# 5,372,497 \\
\text { Process and Apparatus for } \\
\text { igniting } \\
\text { a burner in an Inert } \\
\text { atmosphere. } \\
\text { Issue Date: December 13, } \\
1994\end{array}$ & $\begin{array}{l}\text { F. Rinker } \\
\text { D. Coolidge }\end{array}$ & F. Rinker & $\begin{array}{l}\text { Filed in Japan } \\
29 \text { November } \\
1995\end{array}$ & May 1994 & $\begin{array}{l}\text { Larry } \\
\text { Meenan } \\
\text { Toledo, OH }\end{array}$ & $\begin{array}{l}\text { Amended } 9 \text { Apr } 96 \\
\text { Formal examination by } \\
\text { Japanese patent office } \\
\text { requested. Patent } \\
\text { "Pending." }\end{array}$ \\
\hline 3 & $\begin{array}{l}\text { Process for passivation of } \\
\text { reactive coal char. } \\
\text { Russian Patent } \# 96105953 / \mathrm{Feb} \\
97\end{array}$ & $\begin{array}{l}\text { D. Coolidge } \\
\text { F. Rinker } \\
\text { E. Esztergar } \\
\text { D. Horne }\end{array}$ & F. Rinker & $\begin{array}{l}\text { Filed } 9 / 8 / 95 \\
\text { U.S. Patent } \\
\text { office. }\end{array}$ & May 1995 & $\begin{array}{l}\text { Larry } \\
\text { Meenan } \\
\text { Toledo, OH }\end{array}$ & $\begin{array}{l}\text { U.S. awaiting examiner's } \\
\text { response to latest } \\
\text { amendment filed } 5 \text { Dec } 96 . \\
\text { Filed } 8 \text { Apr } 96 \text { in Japan } \\
\text { Filed } 27 \text { March } 96 \text { in } \\
\text { Russia. Filed } 8 \text { May } 96 \text { in } \\
\text { Uzbekistan. Filed } 15 \mathrm{Apr} \\
96 \text { in Kazakhstan. Filed } 25 \\
\text { July } 96 \text { in Indonesia. } \\
\text { Patent "Pending" in U.S., } \\
\text { Japan, Uzbekistan, } \\
\text { Kazakhstan \& Indonesia. }\end{array}$ \\
\hline 4 & $\begin{array}{l}\text { U.S. Patent \#5,547,548 } \\
\text { Pyrolysis Process Water } \\
\text { Disposition. }\end{array}$ & $\begin{array}{l}\text { M. Siddoway } \\
\text { F. Rinker } \\
\text { E. Esztergar }\end{array}$ & F. Rinker & Filed $7 / 18 / 94$ & May 1995 & $\begin{array}{l}\text { Ned Randle } \\
\text { St. Louis, } \\
\text { MO } \\
\end{array}$ & Issue Date: 20 Aug 96 \\
\hline 5 & $\begin{array}{l}\text { U.S. Patent } \$ 5,582,807 \\
\text { Method and apparatus for } \\
\text { removing particulate and } \\
\text { gaseous pollutants from a gas } \\
\text { stream. }\end{array}$ & $\begin{array}{l}\text { M. Siddoway } \\
\text { C.F. Liao }\end{array}$ & F. Rinker & Filed 11/11/94 & $\begin{array}{l}\text { November } \\
1994\end{array}$ & $\begin{array}{l}\text { Ned Randle } \\
\text { St. Louis, } \\
\text { MO }\end{array}$ & Issue date: Dec 10, 96. \\
\hline 6 & $\begin{array}{l}\text { Method for creating a } \\
\text { hydrocarbon liquid from coal } \\
\text { pyrolysis by condensation of } \\
\text { the hydrocarbon liquid from } \\
\text { the gas phase. }\end{array}$ & $\begin{array}{l}\text { M. Siddoway } \\
\text { A. Cover } \\
\text { J. ODonnell } \\
\text { C. Chang } \\
\text { R. Londrigan } \\
\text { J. Frederick } \\
\text { E. Manning } \\
\text { S. Anderson } \\
\end{array}$ & F. Rinker & $\begin{array}{l}\text { Filed Nov 4, } \\
1994\end{array}$ & $\begin{array}{l}\text { November 9, } \\
1994\end{array}$ & $\begin{array}{l}\text { Ned Randle } \\
\text { St. Louis, } \\
\text { MO }\end{array}$ & $\begin{array}{l}\text { Final rejection received } \\
\text { decision made not to } \\
\text { pursue with U.S. Patent } \\
\text { Office. }\end{array}$ \\
\hline 7 & $\begin{array}{l}\text { U.S. Patent } \# 4,582,511 \\
\text { Spray system for MK dust } \\
\text { suppression additive. (Issued } \\
\text { Apr 15, 1986) }\end{array}$ & $\begin{array}{l}\text { M. Siddoway } \\
\text { C.F. Liao }\end{array}$ & F. Rinker & Filed 7/18/94 & May 1995 & $\begin{array}{l}\text { Ned Randle } \\
\text { St. Louis, } \\
\text { MO }\end{array}$ & $\begin{array}{l}\text { Original Patent Expires } \\
2003 \text {. Decision made to } \\
\text { not pursue with US Patent } \\
\text { Office. }\end{array}$ \\
\hline 8 & $\begin{array}{l}\text { U.S. Patent } \# 5,601,692 \\
\text { Process for treating non-caking } \\
\text { coal to form passivated char. } \\
\text { Russian Patent } \# 96105954 / \mathrm{Feb} \\
97\end{array}$ & $\begin{array}{l}\text { F. Rinker } \\
\text { E. Esztergar } \\
\text { D. Coolidge } \\
\text { D. Horne }\end{array}$ & F. Rinker & $\begin{array}{l}\text { Filed } 12 / 1 / 95 \\
\text { U.S. patent } \\
\text { office. }\end{array}$ & April 1996 & $\begin{array}{l}\text { Larry } \\
\text { Meenan } \\
\text { Toledo, OH }\end{array}$ & $\begin{array}{l}\text { Issue Date: } 11 \text { Feb } 97 \\
\text { Filed } 12 \text { April } 96 \text { in Japan } \\
\text { Filed } 27 \text { March } 96 \text { in } \\
\text { Russia. Filed } 8 \text { May } 96 \text { in } \\
\text { Uzbekistar. Filed } 15 \text { Apr } \\
96 \text { in Kazakhstan. Filed } 25 \\
\text { July } 96 \text { in Indonesia. } \\
\text { Patent "Pending" in Japan, } \\
\text { Uzbekistan, Kazakhstan \& } \\
\text { Indonesia. }\end{array}$ \\
\hline 9 & $\begin{array}{l}\text { Lean Fuel combustion control } \\
\text { method. }\end{array}$ & $\begin{array}{l}\text { D. Coolidge } \\
\text { T. Kuhn } \\
\text { J. Powers } \\
\text { F. Rinker }\end{array}$ & F. Rinker & $\begin{array}{l}\text { Filed } 10 / 30 / 95 \\
\text { U.S. patent } \\
\text { office. }\end{array}$ & $\begin{array}{l}\text { September } \\
1995\end{array}$ & $\begin{array}{l}\text { Ned Randle } \\
\text { St. Louis, } \\
\text { MO }\end{array}$ & $\begin{array}{l}\text { Formal Examination } \\
\text { Requested. Patent } \\
\text { "Pending." Status inquiry } \\
\text { to examiner has been sent } \\
\text { in Nov } 96 \text {. Second Letter } \\
\text { sent Feb 97. }\end{array}$ \\
\hline
\end{tabular}

Note: DOE patent waiver issued for all 


\subsection{Process Flow Diagrams and Material Flow Balance}

\section{Summary}

The processing parameters for applying the LFC Technology to Powder River Basin coals have been compiled from over $4 \frac{1}{2}$ years of operating the 1,000-ton/day ENCOAL Plant. This information was combined with TEK-KOL Development Center data to predict the material balance for Buckskin coal processed in a 5,000-metric ton/day LFC module. A material balance gives an estimate of product yields and qualities based on a single set of processing conditions. Variations in processing parameters will affect these results, and the ENCOAL Plant has demonstrated the flexibility of operating parameters in the LFC Process.

To make design decisions for the commercial plant, a material balance was calculated using Hyprotech's process simulator, HYSIM. HYSIM cannot utilize an in-depth characterization of a solid, nor can it accurately simulate the pyrolysis reaction with a stand-alone unit operation. Consequently, the simulation had to be complemented with information from the ENCOAL Plant to accurately predict product yields and qualities. The product recoveries predicted for Buckskin coal in the material balance are 0.45 barrels $\mathrm{CDL}$ and 0.5 tons of PDF/ton of coal processed. For the same coal, ENCOAL Plant yields have been demonstrated to be 0.51 barrels of CDL and 0.5 tons of PDF. Laboratory data and a plant test of North Rochelle coal established similarities between Buckskin and North Rochelle products and processing conditions. As a result, the material balance did not have to be adjusted for the differences between Buckskin and North Rochelle coal.

\section{Introduction}

The transition between the ENCOAL Plant (as described in Section 5.1) and the proposed LFC Commercial Plant presented a number of challenges that were met with process and design changes. (Refer to Figure 5.2.1 for an overview of the Powder River Basin commercial module.) Variations arose with the first step of the process: coal fed into the ENCOAL Plant is screened to remove oversize and undersize materials that are then returned to the mine. However, a 15,000-metric ton/day commercial plant would return much greater quantities of fine coal to the mine, affecting overall mine product quality and presenting problems in shipping and handling. In addition, the screen used at the ENCOAL Plant is the largest made; scaling-up the current operation would require many parallel trains of equipment, an extremely expensive proposition. To solve this problem, designers replaced the pre-screening with a "vibrating grizzly," which separates and layers the coal on the grate, the larger pieces directly on the grate, the smaller pieces above the larger. This arrangement is intended to keep fine materials from plugging or trickling through the grate. During drying, fines will fluidize, leave the process and be recovered by a bank of cyclones that are much larger than ENCOAL's current four-unit dryer cyclone. From the cyclones, the fines will be pneumatically conveyed to fuel a nearby cogeneration plant, or to an agglomeration system that will recover the fines for later use as fuel. 


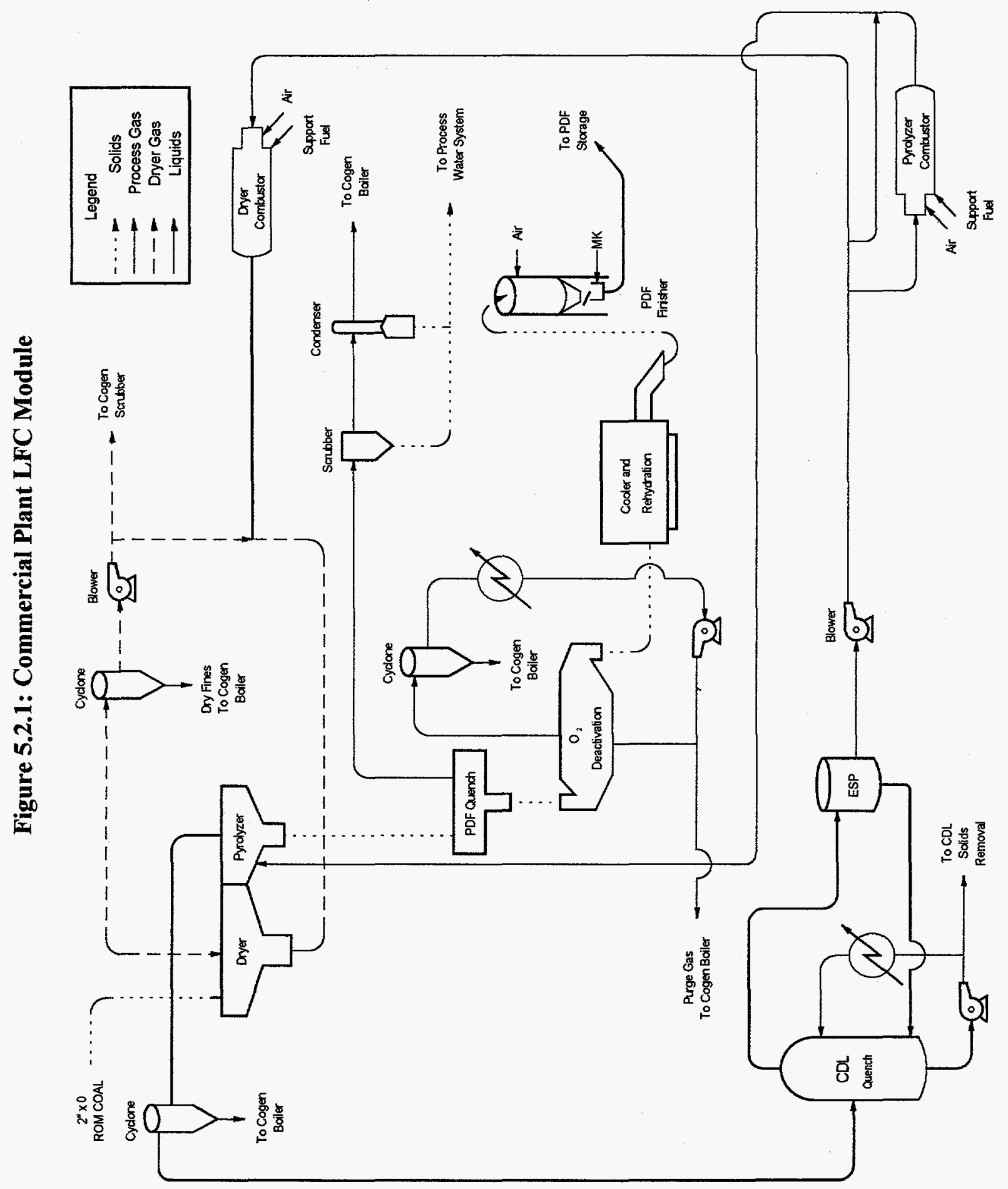


A second variation follows changes in the screening step and in a combined dryer and pyrolyzer piece of equipment: at the ENCOAL Plant, properly sized coal moves onto a Salem Corporation rotary hearth, where drying and pyrolyzing occur in discreet steps in separate pieces of equipment. In the commercial system, the ROM coal is not sized prior to entering the facility, but is segregated just prior to entering the dryer. This means that all of the ROM coal is processed in the facility, not just the $+1 / 8 \times 2$ inch coal that is currently processed in the demonstration plant. Once segregated, the coarse coal is distributed on a large rotary grate as the bottom layer, and the fine coal is placed on the top of the coarse coal to form the top layer. The coal is then dried and pyrolyzed using a single combined dryer and pyrolyzer grate proposed by Mitsubishi Heavy Industries. The drying and pyrolysis steps remain discreet and separate steps, but are performed on one piece of equipment. Such multi-step processing on a single circular grate has been demonstrated extensively by MHI in commercial-scale coke quenching applications in Nagoya, Japan. TEK-KOL and MHI realize that changes in the screening process and equipment design may produce some technical difficulties, but in anticipation, $\mathrm{MHI}$ has already begun a testing program to identify and mitigate any possible problems.

The remainder of the commercial-scale process parallels the demonstration-scale process up to the stabilization segment. Stabilization, returning the char to the same stable state as the parent coal, involves three steps: deactivation at high temperatures, cooling and rehydration, and finishing. As in the ENCOAL Plant process, the deactivation loop in the commercial plant design contacts the solids with a gas stream containing a controlled amount of oxygen to allow oxygen absorption. This step, termed oxidative deactivation, begins to stabilize the reactive solid product. Replicating this process in the larger commercial plant would require numerous VFBs to handle the increased output. To keep down the number of equipment pieces in the commercial plant, TEK-KOL is testing a single quiescent bed concept based on Salem Furnace's "doughnut" design for use as a deactivator. After the deactivation unit, the solids are then cooled and rehydrated to near their ASTM equilibrium moisture content. The fines recovered by the bank of cyclones in the deactivation unit are returned to the product stream prior to rehydration. In the commercial plant design, the cooled PDF is then conveyed to the final finishing unit to ensure stability.

In this final step, pilot tested at the ENCOAL Plant, the solids are contacted with an oxidizing gas stream. Gas temperatures and flowrates are controlled to encourage the maximum oxidation rate without the risk of solid ignition. The gas stream humidity is controlled to keep the solids from adsorbing or desorbing any water. The residence time is sufficient to allow the solids to adsorb enough oxygen to prevent significant additional oxygen uptake, greatly diminishing the risk of spontaneous ignition once the solids are discharged from the plant. Because the solids have minimal free moisture and tend to be dusty, a proven dust suppressant is added as the PDF as it is transferred to a large storage barn.

Other variations occur on the gas side of the LFC process. In the ENCOAL Plant, hot gas produced in the pyrolyzer is sent through a single specially designed cyclone for removal of the particulates. In the commercial plant, multiple cyclones will handle the large flowrates. The new cyclones will be more efficient and have higher pressure drops to prevent solids-carryover into the CDL and prevent duct plugging. As stated above, the fines from the bank of pyrolyzer cylcones are 
pneumatically conveyed either to a fines agglomeration unit for recovery as PDF, or to a nearby cogeneration unit for use as utility boiler fuel.

In the commercial plant design, CDL captured by the quench tower is passed hot through a centrifuge to remove $90 \%$ of the entrained solids in the oil. The CDL is then pumped to storage. This centrifuge process was pilot tested in the ENCOAL Plant, and these test data were used to design the commercial plant systems.

Because of larger gas flows, multiple electrostatic precipitators recover any remaining liquid droplets and mists from the gas leaving the condensation unit in the commercial plant design. The new design multiplies the original three electrostatic precipitators to handle larger gas flows, enhance oil recovery and prevent damaging mists from entering the rest of the equipment.

In the original process design, a single liquid was produced and sold. The commercial plant process differs: after condensation, the CDL undergoes further upgrading, producing four liquids. In this upgrading process, the oil is sent to a crude cresylic acid column where most of the cresylic acids are separated and collected. The oil is then sent to a tar vacuum flasher for recovery of the pitch fraction. The stream remaining after the cresylic acid and pitch recovery is sent through a two-stage naphtha extraction. Here, two additional fractions will be recovered, namely refinery feedstock and an oxygenated middle distillate. A portion of the oxygenated fraction is used as make-up fuel in the combustors.

The use of this oxygenated middle distillate improves on the ENCOAL Plant process. In the current ENCOAL and commercial plant designs, $70 \%$ of the process heat is provided by noncondensed hydrocarbons in the pyrolysis gas. In the ENCOAL design, the remaining $30 \%$ of support fuel was provided by natural gas, an expensive product that may not be readily available in all locations, especially foreign plant sites. The oxygenated middle distillate, not split off in the orignal process, is an ideal fuel. It is the lowest value CDL product, making it inexpensive, and is readily available from the process.

Incorporating the oxygenated middle distillate as make-up fuel in the combustor operation necessitates changes in combustor controls, and these changes are currently under study.

As stated in the Summary, the material balance was simulated using Hyprotech's HYSIM process simulator. This material balance is a summation of data generated at the TEK-KOL Development Center and process data obtained and analyzed from actual operation of the ENCOAL Plant. The product yields generated in the laboratory generally match Plant data; however, if the data differed, the Plant data were considered more accurate and were used in the development of the material balance. The processing conditions used in the simulation are in agreement with operating parameters in the ENCOAL Plant.

Despite this careful collection and input of laboratory and plant data, some difficulties in the material balance remained. The large array of hydrocarbons in pyrolysis gas makes it extremely complex and almost impossible to characterize. However, pyrolysis gases yield two measurable products: 
noncondensable gases and oil. By aiming to match yields of noncondensable gases and oil rather than to actually characterize the gases from the pyrolysis reaction, the simulation could predict a material balance with increased accuracy. Design based on simulated material balances can be further refined by examining the relationship between the two pyrolysis gas product streams. The streams are inversely correlated: increased gas flows reduce oil recovery, and more oil recovery is accompanied by decreased gas flows.

The oil (CDL) recovery predicted by the simulation is 0.45 barrels/ton, but the ENCOAL Plant has actually yielded 0.51 barrels of CDL/ton of coal processed. The reason for this discrepancy is twofold. First, the simulated pyrolysis reaction tends to predict lower oil than is actually recovered, and higher heating value noncondensable gas. Second, the simulation shows a slightly higher production of pyrolysis water than the plant data and laboratory results indicate.

Because increased gas flow means less CDL recovery, assuming a 0.45 barrel/ton recovery of CDL will mean more noncondensable pyrolysis gas, and for this reason, a larger gas processing system was designed. If CDL recovery is 0.51 barrels/ton, as has been demonstrated at the ENCOAL Plant, gas flow will be less.

It is important to note at this point that the predicted quantity and quality of recovered products can be changed in the simulation by manipulating gas constitutents. For example, one of the gases that leaves the coal bed is pyrolysis water. By adjusting the pyrolysis water, the ratio of condensed gases to noncondensed gases is affected, subsequently affecting the simulated production of CDL. Less pyrolysis water means more CDL. Despite the simulated predictions, however, plant data indicate that the commercial plant will show this higher CDL recovery, and plant economics are based on higher CDL recovery figures.

TEK-KOL has a simulation program, LFC SIM (Level 0), which is capable of predicting pyrolysis bed performance. This tool will be used in future design analysis to better predict products of pyrolysis and to utilize the variability of the process.

\section{Data Section}

Analysis at the TEK-KOL Development Center showed no physical or chemical differences between Buckskin coal and North Rochelle coal that would require significant design changes. A commercial plant referenced to Buckskin coal will be able to incorporate North Rochelle coal readily.

Laboratory analysis did reveal some slight differences. The higher oxygen content of the North Rochelle coal, as quantified by the oxygen to carbon ratio, appears to generate a greater amount of noncondensable gas dominated by carbon dioxide and carbon monoxide. This make-up would lower the heating value of the recycled pyrolysis gas stream. However, elemental analysis on North Rochelle coal indicates that less pyrolysis water should be produced, increasing CDL recovery.

After laboratory analysis, 2,500 tons of North Rochelle coal were processed at the ENCOAL Plant. Originally, the sample was to have been tested using new processing parameters, but because the 
coals were so similar, the parameters were not adjusted. Results obtained from processing the North Rochelle coal at these conditions indicate that slightly less CDL is recovered and the PDF has higher volatile matter. This indicates that at under Buckskin processing conditions, the North Rochelle coal was slightly underpyrolyzed. To obtain the same product yields and quality as Buckskin coal, the North Rochelle coal needs to be pyrolyzed to a slightly greater degree than what was accomplished at the Buckskin coal operating parameters.

\section{Conclusion}

This section describes the process and provides data for the 5,000-metric ton/day LFC module for Buckskin coal. Information from the 1,000-ton/day ENCOAL Plant was combined with laboratory data to formulate the basis for the LFC Commercial Plant. Data generated at the ENCOAL Plant and the TEK-KOL Development Center agree on important concepts, indicating that the scale-up to the commercial-size plant entails little risk. Laboratory data and process simulation seem to confidently predict the scale-up, and to predict and control differences in product quality and recovery from one coal to another. Furthermore, because the material balance is based on $4 \frac{1}{2}$ years of actual operating experience with Buckskin coal, plant performance results carry special weight.

\subsection{Equipment Lists and Equipment Data Sheets}

\section{Summary}

The equipment list and data sheets for this Feasibility Study were jointly produced by TEK-KOL and MHI. These documents define the project scope-of-work and allow for consistent transfer of information between the engineering disciplines.

\section{Introduction}

The equipment list includes all numbered equipment items necessary to operate a stand-alone LFC commercial plant. This includes all major LFC process equipment, supporting subsystems, off-sites utilities, CDL upgrading, solids handling and mobile equipment. The equipment list was developed using a combination of process information from the heat and material balance, the design basis document, budget quotes from major equipment suppliers, results of in-depth engineering studies, and scaling-up from the ENCOAL Plant. As much as possible, critical LFC process components were specified based upon ENCOAL Plant experience in successfully operating similar equipment.

\section{Data}

Equipment data sheets were produced for the major LFC process components listed in Table 5.3.1. Comprehensive data sheets were developed for these items as they were the most critical process components, and the largest cost impact components of the Powder River Basin Phase II Study. These data sheets were used to obtain reliable, accurate vendor quotes for equipment supply. 
Data sheets were not produced for the remaining equipment items found in the equipment list. Although some areas such as solids handling and CDL upgrading included many large components and had a significant cost impact, enough information was available from recent installations or engineering studies to adequately estimate and size the equipment without developing data sheets for vendor quotation.

The remaining equipment data sheets, which consist mostly of support subsystems and off-sites utilities components, will be developed in more detail by the engineering contractor for the commercial plant. Estimates for equipment in these areas were made based upon information from the heat and material balance, the design basis document, and scale-up from the ENCOAL Plant.

\section{Conclusion}

The equipment list and data sheets produced for this Feasibility Study summarize the extensive engineering efforts made to quantify, size, specify and price the necessary equipment components needed to operate an LFC commercial plant. The equipment list and data sheets are complete for all critical LFC process components, but may be improved in the areas of deactivation and finishing as more engineering data are obtained from operating and testing in the ENCOAL Plant.

Equipment contained in the areas of solids handling and CDL upgrading were not individually quoted, but were estimated as overall systems based upon recent detailed engineering studies or actual installations. The risk of error in cost is therefore low, but a more complete equipment list and possibly a more accurate estimate could be obtained if these areas were broken down into components rather than systems.

More detailed engineering is required on the plant support subsystems and off-sites utilities before data sheets can be produced to obtain vendor quotes. However, the components included in these areas are technically proven and small in cost when compared to the critical LFC process equipment, reducing the risk of error. 
TABLE 5.3.1: Index of Equipment Data Sheets

\begin{tabular}{||l|l|c||}
\hline \hline & & Produced By \\
\hline 1. & Circular Grate (Dryer \& Pyrolyzer) & TEK-KOL/MHI \\
\hline 2. & Blower \& Fan & MHI \\
\hline 3. & Electrostatic Precipitator & TEK-KOL/MHI \\
\hline 4. & Cyclone & MHI \\
\hline 5. & Combustor & MHI \\
\hline 6. & Overhead Travelling Crane & MHI \\
\hline 7. & Grizzly Screen & MHI \\
\hline 8. & Pan Conveyor & MHI \\
\hline 9. & Chain Conveyor & MHI \\
\hline 10. & Pneumatic Conveyor & MHI \\
\hline 11. & Heat Exchanger & MHI \\
\hline 12. & Quench Column & TEK-KOL \\
\hline 13. & Quench Table & TEK-KOL \\
\hline 14. & Oxidative Deactivation Unit(s) & TEK-KOL \\
\hline 15. & Rehydration/Cooling Unit(s) & TEK-KOL \\
\hline 16. & Finishing Unit(s) & TEK-KOL \\
\hline 17. & Flue Gas Desulfurization Equipment & TEK-KOL \\
\hline \hline
\end{tabular}

\subsection{Site Layout and Support Facilities}

\section{Summary}

The site layout and support facilities sections of this Study were produced by TEK-KOL engineers following the guidelines of the design basis document. The main LFC Commercial Plant facilities were placed inside the North Rochelle Mine rail loop, integrated with the mine's solids handling system. A site plot plan developed according to this concept is illustrated in Figure 5.4.1. 
Figure 5.4.1: LFC Commercial Plant Plot Plan.

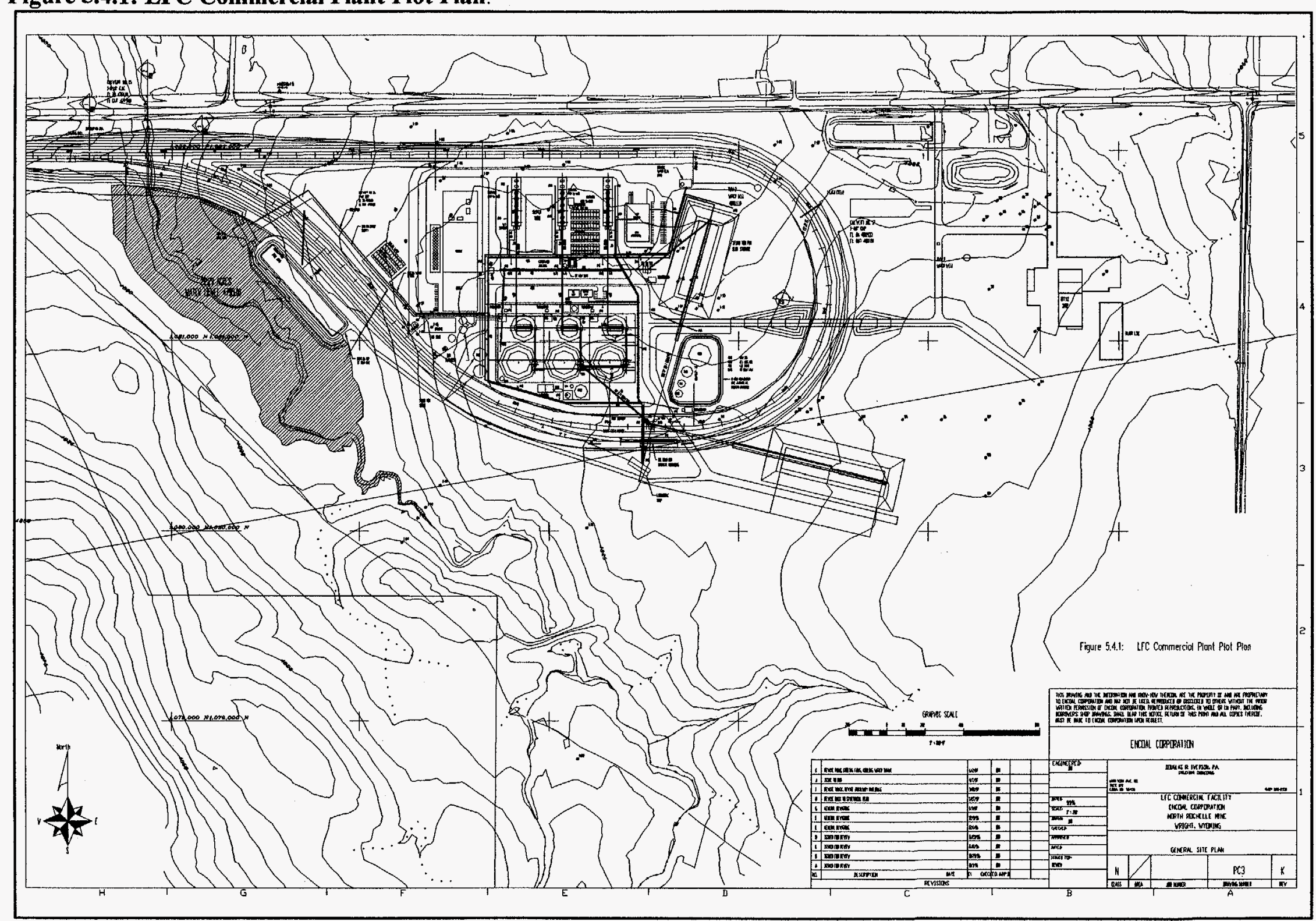




\section{Introduction}

The site layout includes all plant and support facilities required for the operation of a stand-alone LFC Commercial plant. This consists of the main LFC Plant, off-sites utilities, CDL upgrading, tankage, solids handling, mobile equipment, miscellaneous personnel and facility support structures, a rail siding and liquids loadout facility.

The solids handling layout and equipment were chosen using the basic design assumptions listed in the design basis document. The solids handling system includes all the equipment and structures necessary to obtain raw coal from an expanded mine storage barn, transport feed coal into the plant, transfer PDF out of the plant, store PDF product, and load out PDF using the mine batch load out system. The solids handling facilities also include a system to handle below specification PDF. Existing mine sampling systems were utilized rather than including separate raw coal and PDF sampling systems.

\section{Data}

Major impacts on the design and cost of the solids handling system consisted of:

1. The required storage capacity in and out of the LFC Plant,

2. Distance between the mine feed coal transfer point to the LFC Plant raw coal storage,

3. Distance between the LFC Plant, PDF discharge, and the PDF batch loadout located on the mine rail loop,

4. Overall height of the LFC Plant and finishing structures,

5. Use of slot-type storage versus silo storage for PDF , and

6. Minimum sizing of belt conveyors to be 36 inches wide with a maximum angle of incline of 16 degrees.

Unit costs for most of the solids handling components were estimated using data from a Roberts and Schaefer Company design proposal prepared for the North Rochelle Mine in 1995. These costs were compared to other Zeigler Coal Holding Company installations, adjusted to present day dollars, and input as unit costs for the purposes of this Study.

The LFC Commercial Plant rail siding layout consists of two parallel tracks totalling over 3 miles of storage for rail cars. These tracks were spaced 15 feet apart, (center to center, minimum required space being 13 feet), and were oriented to run adjacent with the proposed mine rail loop. The design also included a locomotive warming shed and a covered loading and unloading area, with the ability to load up to four rail cars at the same time. Estimated costs for the rail siding were assembled using 
vendor quotes to install track and ballast on a dollar/foot basis, and switches on a dollar/switch basis. Grade work and construction of the subballast for the siding was not included in this section.

A complete list of all structures was jointly developed by TEK-KOL and MHI, and includes all structures needed for the main process equipment, supporting subsystems, electrical power distribution, solids handling, CDL upgrading and personnel buildings. The function, dimension and loading of each structure were analyzed individually to determine the type of construction needed in each case. Costs were estimated for smaller structures based upon a dollar/square foot or vendor quote. MHI engineering factors were used for estimating the main LFC buildings. Foundations and heating, ventilation and air conditioning were considered as part of the building estimate in all cases.

Tankage requirements to support the LFC Commercial Plant were estimated using the design basis product and chemical storage requirements, CDL product flows from the heat and material balance, scale-up from the ENCOAL Plant, and duplication of facility support tankage found on the Buckskin Mine site where the ENCOAL Plant is located. All storage tanks estimated were divided into two categories. Bulk storage tanks were typically 300,000 gallons or greater in capacity and were located in the tankfarm containment areas adjacent to the CDL upgrading facilities and rail loop. Day storage tanks were considered to be less than 300,000 gallons capacity and were located throughout the plant site. Cost estimates were based upon vendor quotation in 1996.

Mobile equipment needed for the LFC Commercial Plant was estimated based on the number of personnel, operating experience at the ENCOAL Plant, and maintenance of the road and rail system for the stand-alone facilities. Cost estimates for all mobile equipment were obtained either from vendors or recent Zeigler Coal Holding Company purchase records. This system does not include the installation of a fuel island and ready-line in support of the mobile equipment fleet, but uses the proposed mine fuel island to support the fleet.

\section{Conclusions}

Site layout and support facilities are fairly specific to a given location. Every potential host site for an LFC Commercial plant will require substantial site assessment work prior to finalizing a plant site. However, many of the same assumptions used to develop the Powder River Basin LFC Commercial Plant layout may transfer to other locations, and will require only minor modifications based upon the site location. Main areas impacted by location are the solids handling system, railroad track and miscellaneous structures.

Cost estimates made for the support facilities discussed in this section are heavily supported by recent cost data or extensive engineering studies. Some consideration could be given to modifying some assumptions affecting the layout of the solids handling equipment, however, as it is the largest cost item of the support facilities.

Other savings in capital costs could be realized if the LFC Commercial Plant were built and operated integrally with mine facilities. Facility personnel structures, mobile equipment and joint plant water systems are some examples of possible areas of duplication with a mine. 
TABLE 5.4.1: Index of Structures and Buildings

\begin{tabular}{|c|c|c|}
\hline & Description & Lead Role \\
\hline $\begin{array}{l}\text { BL la } \\
\text { BL 1b } \\
\text { BL 1c }\end{array}$ & $\begin{array}{l}\text { LFC I Structure } \\
\text { LFC II Structure } \\
\text { LFC III Structure }\end{array}$ & $\begin{array}{l}\text { MHI } \\
\text { MHI } \\
\text { MHI }\end{array}$ \\
\hline $\begin{array}{l}\text { BL 2a } \\
\text { BL 2b } \\
\text { BL 2c }\end{array}$ & $\begin{array}{l}\text { LFC I Finishing Structure } \\
\text { LFC II Finishing Structure } \\
\text { LFC III Finishing Structure }\end{array}$ & $\begin{array}{l}\text { TEK-KOL } \\
\text { TEK-KOL } \\
\text { TEK-KOL }\end{array}$ \\
\hline BL 3 & Control Room Building & TEK-KOL \\
\hline BL 4 & Admin, Shop, Warehouse & TEK-KOL \\
\hline BL 5 & Potable Water Building & TEK-KOL \\
\hline $\begin{array}{l}\text { BL } 6 \mathrm{a} \\
\text { BL } 6 \mathrm{~b}\end{array}$ & $\begin{array}{l}\text { Locomotive Building } \\
\text { Covered Loadout }\end{array}$ & $\begin{array}{l}\text { TEK-KOL } \\
\text { TEK-KOL }\end{array}$ \\
\hline BL 7 & Lime Transfer Building & TEK-KOL \\
\hline $\begin{array}{l}\text { BL 8a } \\
\text { BL 8b } \\
\text { BL 8c } \\
\text { BL 8d }\end{array}$ & $\begin{array}{l}\text { Main MCC/Switchgear Building } \\
\text { MCC - CDL Upgrading } \\
\text { MCC - Batch Loadout/PDF Storage } \\
\text { MCC - Raw Coal Storage }\end{array}$ & $\begin{array}{l}\text { TEK-KOL } \\
\text { TEK-KOL } \\
\text { TEK-KOL } \\
\text { TEK-KOL }\end{array}$ \\
\hline BL 9 & Substation Building & TEK-KOL \\
\hline BL 10 & Cooling Water Building & TEK-KOL \\
\hline BL 11 & Waste Water Pond Building & TEK-KOL \\
\hline BL 12 & Process Water Building & TEK-KOL \\
\hline BL 13 & CDL Upgrading Building/Pad & TEK-KOL \\
\hline BL 14 & Air Compressor Building & TEK-KOL \\
\hline BL 15 & LFC Nitrogen Building & TEK-KOL \\
\hline $\begin{array}{l}\text { BL } 16 a \\
\text { BL } 16 b \\
\text { BL } 16 c\end{array}$ & $\begin{array}{l}\text { LFCI Finishing Scrubber Building } \\
\text { LFCII Finishing Scrubber Building } \\
\text { LFCIII Finishing Scrubber Building }\end{array}$ & $\begin{array}{l}\text { TEK-KOL } \\
\text { TEK-KOL } \\
\text { TEK-KOL }\end{array}$ \\
\hline BL 17 & Guard House & TEK-KOL \\
\hline
\end{tabular}




\subsection{Site Preparation and Drainage}

\section{Summary}

This section addresses topsoil removal, excavation and grading work required for the construction of the LFC Commercial Plant and related facilities. TEK-KOL engineers estimated site preparation costs based on a Site Layout (see Figure 5.4.1) as described in Section 5.4, experience at the ENCOAL Plant, and unit costs obtained from recently completed jobs. Estimates for the LFC structure foundations and subfoundations were the responsibility of $\mathrm{MHI}$ and fall outside the scope of this section. Also, foundations for smaller buildings, slot storage facilities, railroad facilities, conveyors, pipelines and bulk storage facilities are addressed in other portions of the Feasibility Study.

While the unit costs employed in this estimate are well documented, the estimated acreages and excavation quantities are somewhat sensitive to exact plant location. The topography and soil horizons at the actual site selected could affect the total cost estimate.

\section{Introduction}

Site preparation includes topsoil removal, rough grading, mass excavation, road and drainage construction, pond excavation and lining, rail siding grade and subgrade, bridge access and fencing. The site plan calls for topsoil removal in the area of the LFC plant, the offsite storage and tank farm areas, along road alignments, and in the area of the reservoir. Topsoil removal costs include clearing and grubbing as required. Rough grading and mass excavation were estimated for building areas and foundations. Grading and excavation for ponds and tank farms were included in those particular estimates.

Key assumptions in developing a site preparation cost estimate involve unit costs, area topography and disturbed areas associated with the LFC plant, roads, lesser buildings, ponds, storage areas and tank farms. Unit costs for cut and fill, road construction, scoria for road surfacing, pond and containment area liner, and fencing were obtained from Triton Coal Company. Topsoil and excavation costs assumed a relatively short haul distance and/or a relatively large cut.

The topography of the commercial plant site was assumed to be similar to the rolling hills of the ENCOAL Plant site. The depth of topsoil was estimated at 26 inches. Disturbed acreages and excavation quantities were estimated based on design requirements for roads, ponds, storage areas and tank farms. Road and fence lengths were based on the Site Layout Plan (Figure 5.4.1).

Pond and tank farm sizes were calculated from the design basis. Specifically, pond size calculations resulted from LFC plant water needs and heat removal requirements. Tank farm size calculations were based on production rates, reserve requirements and shipment or receipt frequencies for raw $\mathrm{CDL}$, upgraded CDL products and chemical bulk storage. 


\section{Data}

Unit costs were applied to soil quantities, road and fence lengths, and pond and tank farm areas to generate a cost estimate for site preparation and drainage.

\section{Conclusion}

The cost estimate for site preparation and drainage was based on the commercial plant design basis document, as well as experience at ENCOAL and Triton. In cases where the two did not agree, the higher cost figure was used. Site topography was well defined, and a geotechnical report compiled for the North Rochelle Mine in 1982 provided fairly detailed soils information in the immediate area of the LFC facility. Based on the quality of this information, capital estimates for this section should be very sound.

\subsection{Piping and Instrumentation Diagrams}

\section{Summary}

This section covers piping and instrumentation diagrams (P\&ID)s that serve to document the LFC Process as currently envisioned in the commercial plant. The P\&IDs were generated by TEK-KOL engineers using the MHI circular grate approach to drying and pyrolysis. With the subsystem flow diagrams as a foundation, the commercial plant P\&IDs were patterned after ENCOAL Plant P\&IDs. They were developed in sufficient detail to document the process, its support systems, major equipment and control schemes, but not in sufficient detail to specify actual construction.

The P\&IDs are divided into three categories: solids handling, main process and supporting utilities and subsystems. Potential design changes to certain components of the process could affect the P\&IDs. Foremost among these are the deactivation, finishing and CDL upgrading systems.

\section{Introduction}

Subsystem flow diagrams were generated by TEK-KOL engineers to show major equipment and overall control logic for each process and support subsystem. The P\&IDs were developed from these flow diagrams, adding major instruments, smaller equipment items, and flow paths for all solids and fluids affecting each subsystem. The P\&ID symbols and overall design approach utilized the ENCOAL Plant P\&IDs for guidance. In their present form, the commercial plant P\&IDs do not contain secondary instruments and associated circuits (e.g, instruments that control secondary fluids such as instrument air and instrument purge). Additional detail will be added as engineering progresses.

The commercial plant P\&IDs were not used for cost estimating; instead the instrumentation and control cost estimate was developed from a scale-up of the ENCOAL Plant. Because the ENCOAL Plant was the first LFC plant and one of its primary purposes was to gather data, it was heavily instrumented. Using this as a basis for estimating instrumentation and control provides a conservative 
cost estimate for the full-scale production facility. Some optimization of scale was obtained however, through the combination of utility systems into one to support a three module LFC Commercial Plant. This allowed for single system instrumentation and control versus three independant systems.

\section{Conclusion}

The P\&IDs provide documentation for key process and support subsystems, showing significant equipment, primary instruments, piping/ductwork and control schemes. The P\&IDs were not used to estimate control and instrumentation cost; rather, those costs were developed by scaling up the ENCOAL Plant instrumentation and controls. Section 5.9 of this report discusses this cost estimate.

It is expected that the current P\&IDs will provide the basis for future refinements to the process and equipment list. These changes, along with greater detail, will be reflected in future revisions to the P\&IDs.

\subsection{Generic Subsystem Drawings}

\section{Summary}

TEK-KOL engineers produced generic subsystem drawings using ENCOAL Plant subsystems as guides. These drawings were produced to aid in the design, layout and description of all plant support utilities and minor plant systems. Once produced, these drawings served as the foundation for the plant piping and instrumentation diagrams discussed in Section 5.6, and aided in the production of equipment and motor lists discussed in Sections 5.3 and 5.9 respectively. These drawings also aided in estimating the cost of individual support systems for the LFC Commercial Plant.

\section{Introduction}

The subsystem drawings include all plant utilities and minor plant systems that will support the operation the LFC Commercial Plant. These drawings also include CDL upgrading, a major facility not discussed in other sections of this study.

LFC Commercial Plant subsystem drawings were developed using ENCOAL Plant subsystems as models. The ENCOAL Plant systems were modified using accumulated operation knowledge and adjusted to fit commercial plant design basis. Nine major plant support subsystems perform a variety of functions.

1. Fire water - a network of underground and aboveground piping that supplies emergency water for fire control throughout the plant site.

2. Nitrogen - a centralized header and piping system supplying an inert gas for vacuum protection, equipment purges and instrument purges. 
3. Glycol Water - a network of aboveground piping that continually circulates a 50/50 glycol/water mixture throughout the plant site. This system removes heat from the raw CDL subsystem, vaporizes liquid nitrogen and supplies heat tracing for all equipment and piping.

4. Cooling Water - continuously circulates pond water through a network of underground and aboveground piping throughout the plant site. Low pressure cooling water is used as a heat exchange medium and washdown water at low plant elevations, while high pressure water is used in higher plant elevations.

5. Utility Air - a network of piping to supply 125 -psig air for maintenance or process requirements.

6. Instrument Air - a network of piping to supply "dry" 125-psig air for control valve and instrument applications.

7. Utility Steam - a network of piping suppyling low-pressure steam throughout the plant for cleanup and light process needs. Cogeneration steam will probably be the source for this purpose, but a small plant boiler was estimated for backup.

8. Process Water - continuously circulates a closed loop of water throughout the plant. This water is designated "process" water as it may come in contact with process gas streams and gather fines particulates and some light hydrocarbons.

9. Vapor Recovery - a blower, carbon filter pack and suction ductwork that collects plant odors from the process water system and vents to atmosphere.

\section{Data}

The commercial plant CDL recovery system varies from the ENCOAL Plant system in two respects. First, the commercial plant design calls for removing solids from CDL before it is sent to storage. This system design, pilot tested at the ENCOAL Plant, utilizes a centrifuge to remove $90 \%$ of the entrained solids from the hot oil.

Secondly, the commercial plant CDL recovery system includes an extensive CDL upgrading facility to produce four CDL products from the raw CDL. These products are crude cresylics, refinery feedstock, fuel oil and pitch as discussed in section 4.2. The CDL upgrading process was jointly developed by TEK-KOL, Dakota Gasification, Beulah, North Dakota, and M.W. Kellogg, Houston, Texas, in 1995. Development of this process used ENCOAL Plant CDL as the laboratory test material. Study results indicated that fractionating CDL into the four above components offers an attractive investment opportunity. Costs for installing a CDL upgrading facility at the ENCOAL Plant were estimated by M.W. Kellogg, and these costs are scaled-up to a common system for the three module LFC Commercial Plant for the purposes of this Phase II Report. 
The commercial plant fines handling conveyance system differs from that used at the ENCOAL Plant. The ENCOAL Plant modified its fines handling system several times because of operational and safety problems, and presently uses a slurry system to pump the fines to a settling pond for disposal. This system has proven adequate and reliable for the ENCOAL Plant since the relatively few fines are generated, and there are no uses for the fines as fuel. However, since the higher-throughput LFC Commercial Plant will generate more fines, the commercial plant design uses inert pneumatic conveyance and storage systems to move fines between plant collection points and end users of the fines. These fines are collected in inert storage bins to be agglomerated and used as PDF, or sold to an adjacent cogeneration facility as fuel. Pneumatic conveyance systems are widely used in industry to transport powdered materials, so this design offers an acceptable solution for recovering the fines for fuel rather than disposing of them. Agglomeration of the fines has also been tested at the ENCOAL Plant, and has indicated that method of fines recovery is feasible.

\section{Conclusions}

The LFC Commercial Plant subsystems drawings were modeled after the ENCOAL Plant subsystems. Improvements growing out of operating experience were incorporated into the commercial versions whenever possible. The deviations from the established ENCOAL Plant systems discussed above are either minor, use proven industrial technology or are heavily supported by in-depth engineering studies.

Future improvements could be made to the subsystems package to include all of the major process loops in the plant. This combination of main process and support subsystems could then be used to train plant operating personnel. This was not completed at this time, as the main process has been adequately covered by the process flow diagram and heat and material balance documents.

\subsection{Plant Profile Drawings}

\section{Summary and Introduction}

Plant profile drawings were jointly developed by TEK-KOL and MHI. These drawings aid in the layout and orientation of main process equipment within the LFC Commercial Plant. When used in conjunction with the process flow diagram, heat and material balance, equipment list and site plot plan, the plant profile drawings serve as valuable tools for transfer of information to the various engineering disciplines. The final Powder River Basin LFC Commercial Plant profile is shown in Figure 5.8.1. 


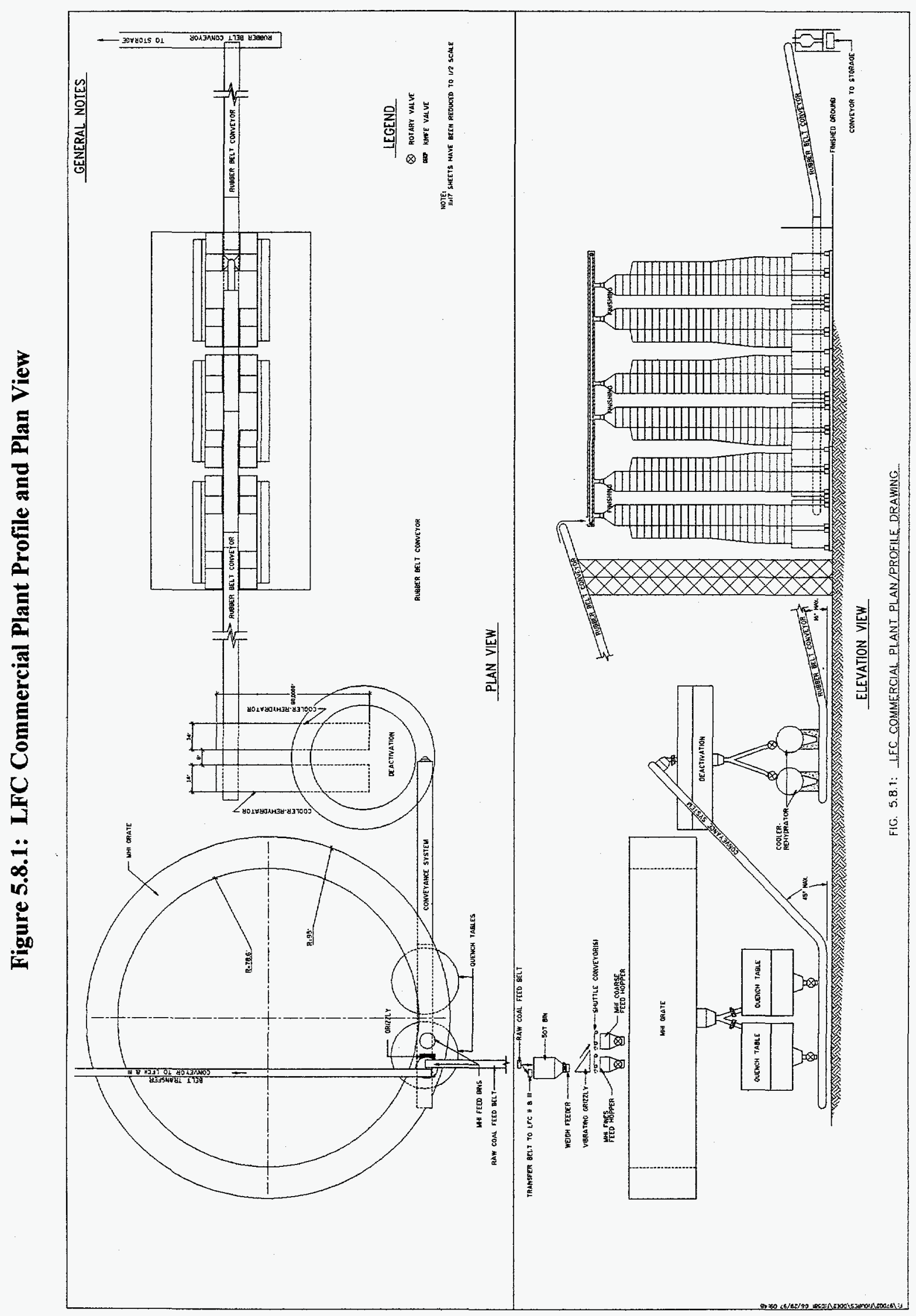




\section{Data}

Several arrangements of main process equipment were studied before settling on the final plant profile. In particular, different arrangements affecting the overall height and dimensions of the plant were investigated. These arrangements varied from a "stacked" plant to a horizontally staged plant and affected the placement of the dryer/pyrolyzer, PDF quench, deactivation, and rehydration/cooling pieces of equipment. The finishing step was placed horizontally on grade to the rehydration/coolers in all cases, and solids were fed to this step on a rubber belt conveyor.

The stacked plant concept had the dryer/pyrolyzer, quench tables, deactivation, and rehydration/cooling equipment arranged vertically and relied on gravity flow between process steps. This version resulted in a tall structure, with the large MHI dryer/pyrolyzer grate located at the top.

The horizontally arranged plant had each processing step located on grade, with conveyance systems to transfer solids between steps. This resulted in a fairly short but large-footprint LFC structure. This arrangement also had a questionable conveyance system of hot, reactive solids between steps, and required a sealing system between all units.

A third arrangement combined the two concepts discussed above. This "split-plant" concept divided the stacked plant layout between the quench tables and deactivation, and connected the solids flow via a pan conveyor. The result was a reasonably tall structure with a moderate footprint.

The three concepts were compared from several different perspectives, and the split-plant version was selected as the final plant profile. MHI conducted a construction cost comparison of the three arrangements and found the split-plant version to be the least expensive. TEK-KOL engineers studied the three concepts from the perspective of adaptability to potential customers, and found the split-plant version to be the most accommodating. Breaking the plant below the quench tables allows for potential construction of an LFC plant without the deactivation, rehydration/cooling, and finishing steps, while leaving the remaining portions of the plant layout essentially untouched. This would fit particularly well with metallurgical applications and sites adjacent to power plants where an LFC plant would be located adjacent to the customer facilities, eliminating the need for these process steps.

\section{Conclusions}

The split-plant profile was chosen for the purposes of this Feasibility Study because this concept was the least expensive arrangement to construct. In addition, it allowed for relatively easy adaption of an LFC plant to metallurgical applications by removing the deactivation, rehydration/cooling, and finishing steps without changing the rest of the plant layout. Applying this technology to future installations makes much of the baseline engineering cost for LFC plant layout unnecessary. This met an overall objective of the Feasibility Study: design standardized facilities to minimize engineering costs of future LFC plants -- not an insignificant cost.

For future plant layouts, the option of feeding the finishing step with a vertical conveyor instead of a 16-degree-incline belt could reduce the overall plant footprint, accommodating LFC plant sites 
where a smaller footprint was required. The Powder River Basin LFC Commercial Plant should stay with the incline belt concept however, since operating experience with vertical belts in this climate has been poor, and overall plant footprint space is not an issue.

\subsection{Electrical, Controls and Instrumentation}

\section{Electrical Summary}

The power system design for the LFC Commercial Plant distributes and transmits electric power to the plant and all its supporting structures. The main components of this system are substations, transformers, starter line-ups, switchgear and Motor Control Centers (MCC)s. A computer model of the power system verified that the proposed design is theoretically sound.

Motor sizing estimates are the biggest risk factors to this design and were estimated conservatively by upsizing existing ENCOAL motor sizes, or were specified by process engineers. The system was proven economically feasible with a comprehensive budget estimate.

\section{Introduction}

To formulate a design basis for a safe, reliable electric power system, many assumptions and design considerations had to be made. One primary design basis was the system layout for the existing ENCOAL facility, which has ensured greater than $99 \%$ power availability for each of the last $4 \frac{1}{2}$ years. A one-line diagram was generated from the original ENCOAL electrical diagrams. This diagram was utilized to generate a computer model of the commercial-size power system using the Distribution Analysis of Power Planning, Evaluation, and Reporting (DAPPER) program. This model generated a Load Center Study, a Load Flow Analysis, a Fault Study and a Demand Load Analysis. These studies ensured that adequate power would be available for operation of the plant and all its equipment.

A motor list derived from the equipment list was utilized in conjunction with a demand load library as system loads in the computer studies. Approximately $35 \%$ of the motor horsepowers were estimated conservatively by upsizing motors from the existing ENCOAL facility, and the remaining motors were specified by process engineers. Motor voltage thresholds were defined and strictly adhered to for this system's specifications: all motors less than $225 \mathrm{~kW} \mathrm{(300} \mathrm{hp)} \mathrm{will} \mathrm{be} 480 \mathrm{~V}$ and defined as low voltage. Motors greater than $300 \mathrm{hp}$ will be $4,160 \mathrm{~V}$ and defined as medium voltage.

General voltage guidelines were specified as follows: $120 / 240 \mathrm{~V}$ for utilities and the Uninterruptible Power Supply (UPS), 277/480 V for plant and offsite lighting. The $X_{\mathrm{o}}$ connection on all transformers will be resistance grounded with a 50-A limit. Illuminating Engineering Society lighting standards will be utilized for this facility.

It was assumed that the proposed LFC Commercial Plant would be located at the North Rochelle Mine site, and equipment was sized and specified accordingly. This assumption dictated that the existing $69-\mathrm{kV}$ power lines would feed the plant substation, using an estimated $1 / 4$ mile of additional 
transmission line. The cost of the system was estimated in two separate segments: TEK-KOL estimated the cost of the system outside plant boundaries, while MHI estimated all the electrical components within plant boundaries. The whole system will provide electric power to all components within the engineering battery limits.

\section{Data}

The Load Center Study indicated that the proposed power system would supply required power reliably and safely. Demand full-load amperages were balanced among the MCCs, which were designed with an 800-A horizontal bus rating and ample expansion space. The Emergency Motor Control Center (EMCC) was minimally loaded for the study. A review of essential equipment must be performed to properly assign loads to the EMCC.

The one-line diagram specifies a host of circuit protection devices to ensure safe operation: fused disconnects, lightning arrestors, air-break over-current trip shunts and manual disconnecting switches. A 500-kVA diesel generator and a 100-KVA UPS were added for emergency backup power, thus ensuring a source of power and lights for controlled plant shutdowns.

A Load Flow Analysis was performed to determine available load capacity on the 4,160-V feed busses and MCCs. The source bus is loaded to 28.3 MVA with a unity Power Factor (PF) and no feeder losses. The heaviest loaded 4,160-V feeder has loads of 4,360 kVA with a 99 leading PF and minimal feeder losses. The CDL-upgrading MCC was the most heavily loaded, at $490 \mathrm{kVA}$ with a 0.95 lagging $\mathrm{PF}$ and virtually no feeder losses.

The Fault Studies proved that the system fault values were reasonable for standard industrial distribution equipment. The $69-\mathrm{kV}$ source bus has a three-phase fault of $837 \mathrm{kA}$ and requires an asymmetrical interrupting current rating of $856 \mathrm{kA}$ at 3 cycles. The typical $4,160-\mathrm{V}$ bus had a threephase fault of $29 \mathrm{kA}$ and required a momentary asymmetrical interrupting current rating of $37 \mathrm{kA}$. In addition, a single line to ground duty of $27 \mathrm{kA}$ was determined for the $4,160-\mathrm{V}$ busses. The largest MCC had a three-phase fault of $25 \mathrm{kA}$ and required a momentary asymmetrical interrupting current rating of $37 \mathrm{kA}$. The single line to ground rating for all MCCs is $50 \mathrm{~A}$.

The Demand Load Analysis showed that the peak demanded loads for the LFC Commercial Plant will be 17.6 MVA or about 2,446 A. These figures are for the commercial plant alone and do not include loads contributed by a cogeneration facility.

The budget estimate proved this system to be economically feasible and within the targeted cost range. The total cost of the system is $\$ 8.6$ million. This study also included a plant communications estimate. The intercom communication system includes 30 multi-channel, loud-speaking telephones that will be installed in the plant and support buildings. This system will also be used to sound alarms alerting plant personnel when equipment is started, when major or minor faults occur, or when plant evacuations or emergency shutdowns take place. Two-way radios were also specified for all plant personnel. 
Although the program uses a load library based on the ENCOAL Plant, which is a good representation of real world devices, it must be noted that the computer model of the specified power system is not completely representative of an actual system. The data from a comprehensive load flow analysis currently being conducted at the ENCOAL facility will be correlated with the existing load library for improved accuracy. Also note that the motor list was originally specified conservatively; therefore, the results from the computer studies may be skewed.

\section{Conclusions}

The Load Center Study proved on a theoretical basis that the specified power system for the LFC Commercial Plant is adequately designed. In order to verify that the system was sized properly, a Load Flow Analysis was performed to compute the load capacity of various components. Balanced and unbalanced Fault Studies were conducted to determine the interrupting ampacity ratings of system components. The Demand Load Analysis indicates that the peak demand loads for the commercial plant, without a cogeneration facility, will be $17,625 \mathrm{kVA}$ or about $2,446 \mathrm{~A}$. The budget quotes established that a system cost of $\$ 8,600,000$ is economically feasible. As engineering work on the LFC Commercial Plant continues, the motor list will need to be refined. This will improve the overall accuracy and credibility of the computer model and verify that the power system is adequately designed.

\section{Controls Summary}

The control system design for the Powder River Basin LFC Commercial Plant is specified to control digital and analog $\mathrm{I} / \mathrm{O}$ points in the field. The main components of this system are Programmable Logic Controllers (PLC)s, digital and analog I/O cards (and associated hardware), operator interface stations, and several personal computers. The system, based on the ENCOAL Plant, has been proved experimentally and theoretically sound.

\section{Introduction}

The control system for the Powder River Basin LFC Commercial Plant was based upon the control scheme for the existing ENCOAL Plant. Several design constraints and assumptions were used in the design of this system. Allen-Bradley PLCs, software, and operator interfaces (ControlView and PanelView stations) will be used for this system. All digital inputs are 24 Volts Direct Current (VDC) except the "Starter Healthy," which is a $120-\mathrm{V}$ isolated input. All outputs for this system will be 24 VDC. Rotating equipment sends a 24 VDC output to an interposing relay for motor starting and stopping. PLC's are used to control all components in the plant, and Figure 5.9.1 depicts the control scheme.

The highest level in the control scheme is Level 0 , which performs data storage and archiving, reporting and expert system control functions. The Level 0 code is written in FORTRAN 77, which has the capability to handle computationally intensive mathematics. Unfortunately, it is cumbersome to modify and understand; therefore Level 0 is currently being rewritten in $\mathrm{C}++$. Level 0 code stores and monitors 130 major plant parameters, operating as an expert control system. In short, it gives 
a scorecard on plant performance. Process simulation algorithms are currently being upgraded to take advantage of recent advances in microcomputer technology. A file server personal computer polls data from the main PLC (Allen-Bradley PLC 5/250) every 5 minutes. These data are stored and sent to a system simulation program. The program makes running parameter recommendations based upon the data it receives from the $5 / 250$ and process simulation algorithms. There are nine major control parameters in the LFC Process that Level 0 predicts; these parameters correspond to changes in temperature or flow in the process loops. Level 0 bases its recommendations on past operating history for given situations. The advantage of Level 0 is that it does not have to be on line to run the simulation program; instead, it runs the system simulation as a background task.

Level I control, the next level of hierarchical control, utilizes a 5/250 PLC as its core processor. This processor acts as a central processing unit for the entire control system. The main functions of the $5 / 250$ are plant interlocking and digital control. The 5/250 contains all digital logic and digital $\mathrm{H} O$, as well as the algorithms to run plant equipment. All rotating equipment (motors, blowers, pumps, conveyors, fans, etc.) and discrete (on/off) valves are controlled by the 5/250 processor. In addition, temperature, pressure, flow measurements, and other parameters not used for control are taken and reported to the $5 / 250$ via analog $\mathrm{I} / \mathrm{O}$.

Level II control includes five PLC 5/40s, which are slaved to the $5 / 250$ as remote I/O. Three of these controllers are used for temperature, level, pressure, and flow control PID (Proportional-IntegralDerivative) loops. These processors also send monitoring information via analog $\mathrm{I} / \mathrm{O}$ to the ControlView operator interface stations. When an interlock is required for a given piece of equipment, information is sent back and forth between the PLC 5/40s and PLC 5/250 as needed. The other two 5/40 PLCs control the dryer and pyrolyzer combustors. Each combustor has two PanelView operator interfaces, one local and one in the control building.

The ENCOAL Plant is monitored with two ControlView stations that are fed information from the PLC 5/250. Raw data values from the PLCs are scaled for display on the operator interfaces. Overall, the PanelView and ControlView operator interfaces are not used for plant control, but enable plant personnel to operate and monitor plant equipment from a remote location. True control resides in the PLC ladder logic. One ControlView station is designated for event detection and plant reporting, which includes trending and data logging. The other Controlview is utilized for monitoring and logging plant alarms. Each complete LFC plant will have a common engineering ControlView station. This ControlView will be used for ladder logic modifications and backup plant operation. The control system for the proposed third-party cogeneration facilities is not part of this estimate.

\section{Data}

The LFC Commercial Plant controls are based on the ENCOAL control system, which has performed extremely well. PLC-based control systems are user-friendly -- easy to learn and understand. Electricians can readily adapt to PLCs because ladder logic resembles components in a motor circuit. Because every I/O point is hardwired, PLCs are easy to troubleshoot. Program troubleshooting and 
editing are convenient because program changes can be tested on line before implementing them into the system. PLCs offer a great deal of power and limitless room for expansion at a low cost when compared to other types of automation systems. Remote racks can be constructed locally to minimize needed wiring.

PLCs also are easily adaptable to changing control needs. Larger processors can be implemented for more memory, or I/O cards can be added or removed as needed. This adaptability minimizes the amount of hardware needed for system control.

Allen-Bradley PLCs are highly reliable even in less-than-ideal environments, and have caused no plant downtime since they were installed at ENCOAL. On the rare occasion that processors fail, they can be changed out in a matter of minutes. In addition, Allen-Bradley has an excellent training program that is readily available, detail oriented and inexpensive.

The existing ENCOAL system has been demonstrated with about 730 digital I/O points, 125 analog I/O points, 90 analog PID I/O points, and 50 combination digital/analog I/O points. This constitutes approximately $210 \mathrm{kBytes}$ of program in the $5 / 250$ and $55 \mathrm{kBytes}$ of program space in the other PLC 5s. Four man-years of program development have been vested in the ENCOAL control system.

\section{Conclusions}

The LFC Commercial Plant control system will perform as well or better than the existing ENCOAL control system. Level 0 control will be even better after the software rewrite. Process simulation algorithms are also being upgraded, thus adding even more accuracy. Overall, past performance indicates that the proposed control system is user-friendly, easy to troubleshoot, inexpensive, reliable and readily adaptable to changing control needs. Each LFC module will be controlled seperately, with a fourth control for common utility support equipment.

Because commercial plant P\&IDs did not contain all detail instrumentation at the time of this Phase II Study, MHI estimated the instrumentation for the LFC Commercial Plant by roughly scaling-up existing ENCOAL Plant P\&IDs. This estimation should be conservative, as the ENCOAL Plant systems contained more than the usual number of instruments for scientific data collection. Capital estimates for the electrical and equipment instrumentation, located in Section 9.2, can be refined when the commercial plant P\&IDs become more detailed. 
Figure 5.9.1: Control Scheme

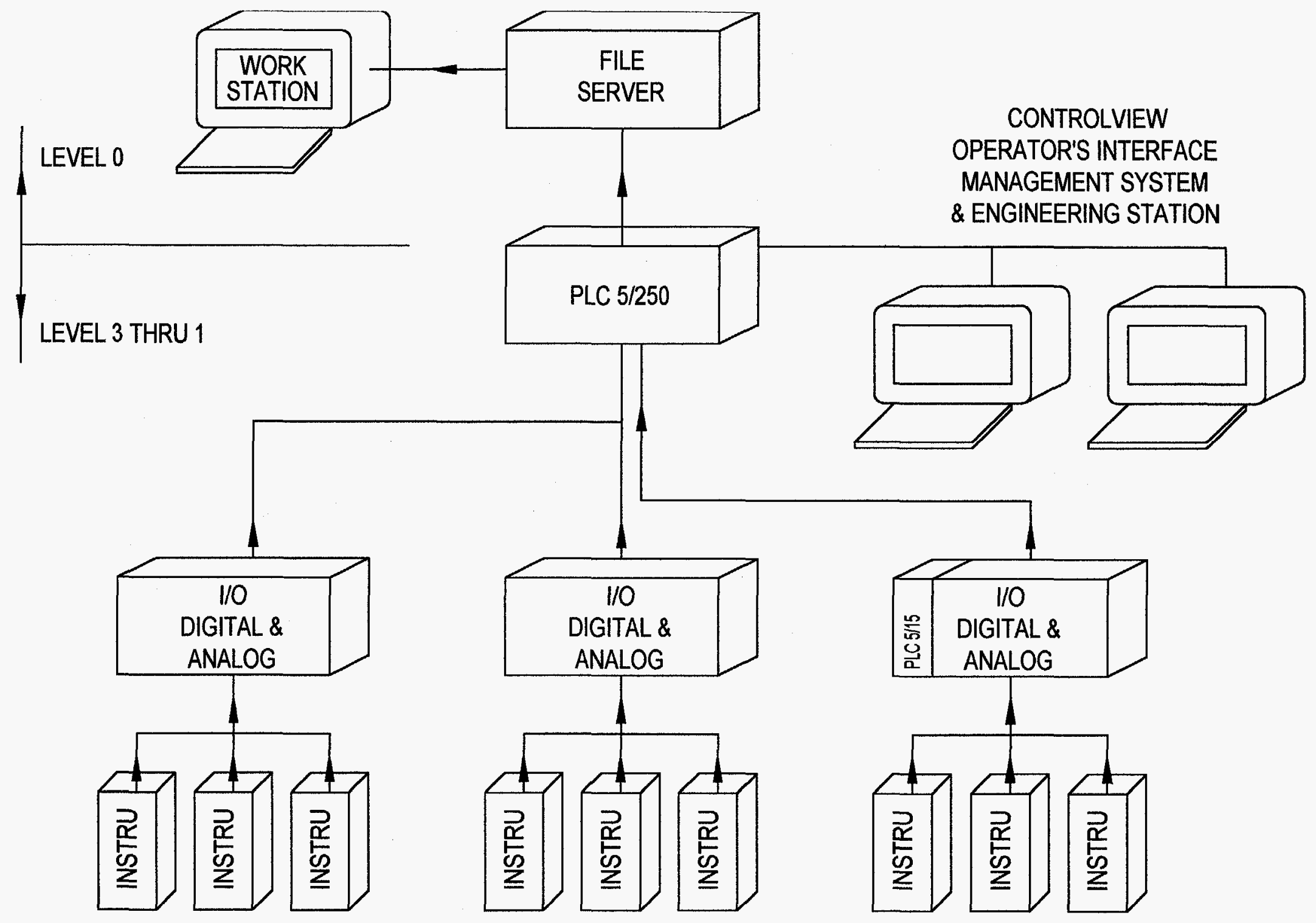




\title{
Section 6.0 Environmental and Permit Requirements
}

\begin{abstract}
Summary
This section covers all significant environmental requirements imposed by public regulatory agencies for the construction of a commercial-scale coal upgrading facility located at Triton Coal Company's North Rochelle Mine in the Powder River Basin of Wyoming. The Phase II permit requirements analysis was performed by TEK-KOL with input from appropriate agencies and environmental consultants. The approach for each permit was to determine the governing authority, define associated data and design requirements, and identify key decision points and issues impacting those decisions.
\end{abstract}

Environmental permit requirements are enforced by both state and federal authorities. Most key State agencies are divisions of the Wyoming Department of Environmental Quality (WDEQ), including the Air Quality Division (AQD), Industrial Siting Division (ISD), Land Quality Division (LQD) and the Water Quality Division (WQD). The State Engineer's Office provides regulatory authority for water appropriation permits. Federal agencies involved in the early stages of permitting are the Mine Health and Safety Administration (MSHA) which will become involved only if certain size requirements are met for a major water impoundment and the U.S. Forest Service (USFS). The USFS owns the surface where the proposed LFC plant site is located. This section addresses permits and activities associated with each of these agencies.

Groundwater availability, application turnaround times and negotiated requirements constitute the principal uncertainties associated with permitting a commercial plant. The experience of ENCOAL, as well as discussions with regulatory agencies and review of existing precedent, indicate minimal permitting risks. Environmental costs and permitting schedules have been estimated based on conservative assumptions.

\section{Introduction}

Prior to authorizing construction of a commercial LFC plant, the WDEQ must issue a construction permit through its AQD, an industrial siting permit through its ISD, a License to Mine from the LQD and a National Pollutant Discharge Elimination System (NPDES) permit from the WQD. Before the plant can operate, groundwater and surface water permits must be obtained through the Wyoming State Engineer. In addition, MSHA may be asked to grant a permit for a large water impoundment if certain size restrictions apply, and a land exchange with the USFS may be necessary in order to site the plant at the planned location.

In order to determine requirements for each permit, TEK-KOL consulted appropriate statutes, regulations, procedure manuals and key officials from WDEQ. In addition to identifying procedural requirements, this effort produced cost and time estimates. Several permit requirements offer some flexibility or provide for negotiation between the applicant and the agency. In these cases, TEK-KOL conducted in-depth discussions with agency personnel and industry consultants to determine the most 
probable compliance level. For the air quality and industrial siting permits, a recent proposal by Kennecott Energy provided supporting precedent. The Kennecott proposal would have utilized the 'PURON" process to produce a high-Btu, pelletized coal byproduct, and projected environmental impacts were similar to those for a large LFC plant. The Kennecott project was permitted, then suspended prior to construction, and those permits were later withdrawn.

The air quality permitting process is determined by three factors. First, a waiver application was approved, relieving TEK-KOL of the 12-month ambient air monitoring requirement. AQD waived the monitoring requirement based on background data already available from mines and power plants in the Powder River Basin.

Second, this Feasibility Study assumed successful application to the Wyoming Environmental Quality Council (EQC) for a PSD (Prevention of Significant Deterioration) baseline area redesignation similar to one granted to Kennecott in December 1994. This redesignation would isolate the LFC Plant (a "major emitter" of particulates) from mines in the basin and avoid triggering for them a PSD baseline date. Mine operators believe exposure to lower particulate thresholds under PSD regulations could limit future expansion. It is important to note that the redesignation is not required for the LFC Plant and does not affect compliance levels for the plant. Also, granting of the redesignation is not guaranteed, and may depend on public pressure, composition of the EQC and support from the Governor's office. Failure to redesignate, though extremely unlikely and in any case not essential for the LFC Plant, could expose the Powder River Basin mines to some risks.

A third air quality permitting issue concerns the state-required Best Available Control Technology (BACT) to limit plant stack emissions of particulates, $\mathrm{SO}_{2}$ and $\mathrm{NO}_{\mathrm{x}}$. The AQD provided TEK-KOL with objective emissions limits for these and other regulated pollutants, based on current BACT. In turn, TEK-KOL generated design specifications and sought prices for plant equipment, such as a flue gas scrubber, that will meet these levels. Although future BACT improvements may result in tighter restrictions, this study assumed the permitting process would not incur undue delays researching available technologies and negotiating with WDEQ. Recent approval of the Kennecott proposal and an 80-MW power plant near Gillette support this assumption.

Taking these three factors into account, an 8-month air quality permitting process seems likely.

The Industrial Siting Act requires a socioeconomic impact analysis and provides for the Industrial Siting Council to assign impact assistance payments to affected counties and municipalities. The money for assistance payments is derived from sales and use taxes generated by the project. Also, companies are expected to negotiate up-front monetary settlements with impacted public entities that do not qualify for impact assistance under the Act, such as school or hospital districts. This Feasibility Study assumed impacts and infrastructure needs similar to those developed for the Kennecott Industrial Siting Permit. Depending on final plant location and prevailing political forces, the Industrial Siting Division has indicated that the impact settlement would likely be far less for the LFC Plant. 
This study assumed a routine procedure for obtaining a groundwater permits to supply water for the LFC Plant. This includes groundwater modeling to quantify the availability of water from various geologic formations, and to predict impacts of pumping from these formations. The Fort Union formation in the vicinity of Gillette is a preferred water source for area mines and municipalities, but has recently been subjected to closer scrutiny and regulation by the State Engineer. Because the permitting process includes public involvement, there is potential for strong opposition from area groundwater users such as the City of Gillette. Modeling studies have shown that locating a plant in the southern Powder River Basin would not impact the Gillette area, allowing the permitting of a Fort Union well. But if necessary, other producing formations such as the shallow scoria aquifer or the deeper Lance/Fox Hills formations could supply the LFC Plant with sufficient water, subject to water quality constraints.

The LQD permit covers site preparation, facilities, water diversion and storage structures, spill prevention/containment, surface water runoff and reclamation requirements. The abundance of mining permits issued in the area provides a reliable basis for estimating permit requirements. Two options are available in obtaining an LQD permit: modify the existing North Rochelle Mine permit to include the LFC facilities, or submit a new and separate application pertaining only to the LFC plant. The most time-consuming components of the second option will include baseline studies for soils, vegetation, archaeology, wildlife, and land use. The first option will allow TEK-KOL to achieve an early construction start and file for a separate permit document later.

One aspect of the proposed site at the North Rochelle Mine is that a land exchange with the USFS will be required prior to authorization to construct. The USFS made a finding that an industrial facility of this kind and magnitude is in conflict with provisions of the Bankhead-Jones Farm Tenant Act and cannot be constructed on federal surface. Therefore, a land exchange with the USFS will be considered as part of the permitting effort.

\section{Data}

Based on information currently available, the permitting process should be completed within 12 to 20 months. The waiver of the air quality monitoring requirement will shorten the pre-construction permitting schedule, but MSHA permitting of the large impoundment, if required, could require an additional 6 months. The cost of obtaining all environmental permits for a commercial LFC plant is estimated at $\$ 900,000$. Up to $\$ 250,000$ of this will serve as up-front impact assistance.

The air quality permit represents the critical path; this permit and the industrial siting permit must be obtained prior to starting construction of the LFC Plant. Approval must also be obtained from LQD prior to performing site grading. Normally, a stormwater runoff permit would be required from WQD prior to construction, but the proposed area is already covered under the North Rochelle permit. Once sediment control structures are in place and a NPDES permit obtained, a stormwater permit will be required only for those areas not contained under the sediment control plan, namely, the railroad corridor to the main line. 
Cost estimates include in-house and consultant time because TEK-KOL sought budgetary estimates from outside consultants for major components of the permitting process. For the air quality permit, these components include BACT analysis, air quality dispersion modeling and stack testing. For the industrial siting permit, an outside consultant provided an estimate for processing the entire permit, including negotiation of impact assistance money to those entities not qualifying for aid under the Act. The actual amount of the impact settlement was estimated based on discussions with the Industrial Siting Division and on the Kennecott settlement negotiated in 1995. For groundwater permits, consultant fees were obtained for well design and for a groundwater supply and yield analysis that utilize a computer model. For the mining permit, TEK-KOL assumed outside consultants would design the storage and containment reservoirs, as well as diversion and drainage structures.

\section{Conclusions}

Based on an in-depth analysis of environmental permitting requirements for an LFC commercial plant constructed in the Powder River Basin, it appears that all permits can be obtained at a reasonable cost and within a 2-year time frame. No fatal flaws have been identified that would preclude the necessary approvals to construct and operate the plant. Several uncertainties such as groundwater availability, background air quality monitoring requirements, PSD baseline area redesignation, impact mitigation settlement and a successful land exchange with the USFS pose cost and schedule risks, but do not threaten the permits themselves. In some cases where appropriate, conservative assumptions were made such that cost and time estimates represent a "worst case."

Permitting schedules can be impacted by the level of public involvement and by the degree of departure in the basic plant design from previously permitted facilities. As of this date, no commercial coal enhancement facility has been constructed in the Powder River Basin; however, air quality and industrial siting permits were issued for a plant proposed by Kennecott Energy, in 1995. These permits provide an appropriate precedent for the proposed LFC Plant, given the similarity of projected environmental and socioeconomic impacts. Along with other factors, the time estimates and negotiated requirements reflect agency experience with the Kennecott permits.

\section{Section 7.0 Commercial Plant Implementation Schedule}

\section{Summary}

The LFC Commercial Plant implementation schedule outlines a 36-month path. The road begins with the environmental permitting process, travels through detailed engineering, procurement and construction, and ends with the commissioning and start-up of the LFC Commercial Plant.

Keys to the implementation schedule's success lie in several factors. It will be important to begin the environmental permitting process as soon as LFC project funding efforts are launched -- 1 year in advance of the start of detailed engineering. Although preconstruction permitting could take as long as 20 months, this Study assumes that permitting will take a "fast track" and be completed in 12 months. The schedule assumes detailed engineering will be completed in 15 months, with 
construction starting in the 6 th month of detailed engineering. This will be followed by start-up and commissioning. The Plant will achieve $50 \%$ plant availability in the first year of operation, $75 \%$ in the second year followed by continuous operation at $90 \%$ availability.

To avoid delays, the environmental permitting process begins as soon as the LFC Project funding efforts are launched. Although it can avoid impact on the implementation schedule, the permitting effort could cost as much as $\$ 900,000$ that would be lost if project financing were not obtained.

\section{Introduction}

Figure 7.1 shows the "LFC Commercial Plant Implementation Schedule." The 36-month schedule moves from the detailed design stage to plant commissioning/start-up and is based on the following assumptions:

1. Procuring project financing coupled with financial due diligence for the project is estimated to take 12 months.

2. It is assumed that the environmental permitting process will take 12 months from the start of the process. Monitoring and data collection are waived in this case, and the mining permits become the critical path for the permitting process. The permitting process will run concurrently with the project financing process, and preconstruction permitting will be complete by the end of the fourth month of the detailed design phase.

3. Detailed design will be conducted by MHI at the MHI Engineering Offices in Hiroshima, Japan, with guidance provided by a 20 -person TEK-KOL engineering team.

4. Process design configurations will be selected before beginning detailed engineering.

5. A process design freeze will be established at month 6 of detailed engineering.

6. The bid/award process for the primary Procurement/Construction Contract will require 6 weeks.

7. The primary procurement/construction contractor will assemble complete engineering bid packages for third party Procurement/Construction. These will consist of five major and 10 to 15 minor contracts. Bidding of the major contracts will require 3 to 4 months, and the minor contracts will require approximately 1 month.

9. Construction will start at month 6 .

10. Long lead equipment items may require up to 50-week delivery times. 


\section{Data}

The environmental permitting process, outlined in Section 6.0 of this report, consists of obtaining various state and federal permits. Air quality, water impoundment and surface water discharge permits are obtained through various divisions of the Wyoming Department of Environmental Quality. Depending on reservoir sizes and jurisdictional issues, impoundments may also require MSHA permitting. In addition, an industrial siting permit will be required from the State of Wyoming to deal with socioeconomic impact. The air quality construction permit will likely require the most time, but because there is a wealth of site information available, it is assumed that a waiver of air quality monitoring and baseline data collection will be granted by the State.

It is anticipated that the air quality permit would be granted within 8 months. In this case, mining permits may become the critical path in the overall environmental permitting process. These permits will need to be prepared early in the detailed engineering phase, as site layout and capacity requirements must precede pond and well permit applications.

The industrial siting permit should require no more than 6 months, subject to final negotiation of impact assistance money.

\section{Engineering}

The Engineering section of the implementation schedule consists of detailed engineering. The TEKKOL Engineering Team, 20 engineers with specialities in mechanical, civil, chemical, process, electrical, instrumentation and computer control, will oversee approximately $\$ 32$ million or 300 manyears worth of detailed plant engineering. The detailed engineering will be performed by $\mathrm{MHI}$ at the MHI Engineering offices in Hiroshima, Japan. During this phase, the two teams will accomplish a great deal. They will complete P\&IDs and flow diagrams, specifications and data sheets, one-line diagrams of electrical substations, and conduit and wiring layouts. The teams will also perform early identification of long lead items; soils mechanics; civil and structural design; mechanical design; piping, instrument and controls design; and equipment selection. Finally, they will assemble bid packages for equipment and construction.

\section{Procurement}

The Procurement section of the implementation schedule includes ordering, expediting and receiving equipment and building materials. During this phase, teams will bid equipment and construction contracts, expedite, accept delivery and inspect equipment. Several major contracts for site civils and foundations, plant erection, electrical/instrumentation, support buildings and structures, railroad and track work and power line construction will minimize the number of construction contracts. Minor contracts for HVAC, testing and fencing will also be issued. Purchasing will consist of acquiring equipment and executing contracts on lump sump prices as much as possible. 


\section{Construction and Start-Up}

The Construction section of the implementation schedule consists of the foundation, miscellaneous civil and structural, installation of equipment, piping and electrical work. During this phase, construction will be broken into logical packages, i.e., earthwork and civil, storage units, railroad work, plant erection, electrical and instrumentation, foundations and buildings. The Project Manager will be responsible for coordinating the various subcontractors. It is anticipated that approximately $\$ 21$ million will be required for construction management with 20 TEK-KOL engineers and construction inspectors taking part in field purchasing, field engineering, assembly of equipment data books, spare parts procurement and inventory, as-built drawings, and initial equipment testing.

The Plant Start-up section consists of precommissioning and commissioning of plant equipment. During this phase equipment is inspected for completeness on installation, leak tests are performed where air/water tightness is required, valve and piping alignment is carried out, together with start-up and check out of machinery. Other topics include responsiveness to local and remote control, development and completion of punch lists, rotation of machinery, initial lube, receiving initial supply of chemicals, setting up spare parts inventory, training of operators and vendor start-up assistance.

\section{Conclusions}

The primary constraints on the schedule are the contracting strategy of Procurement and Construction by a third party and the impact of the environmental permitting process. The overall schedule has been shortened by starting several efforts concurrently: the environmental permitting and project financing efforts commence simultaneously, procurement activities for long-lead items commence during the detailed engineering stage and construction is "fast-tracked" while the detailed design is still going on. The schedule relies on the experiences and lessons learned from construction of the first near-commercial size LFC Plant at the Buckskin Mine by ENCOAL personnel. 
Figure 7.1: Commercial Plant Implementation Schedule

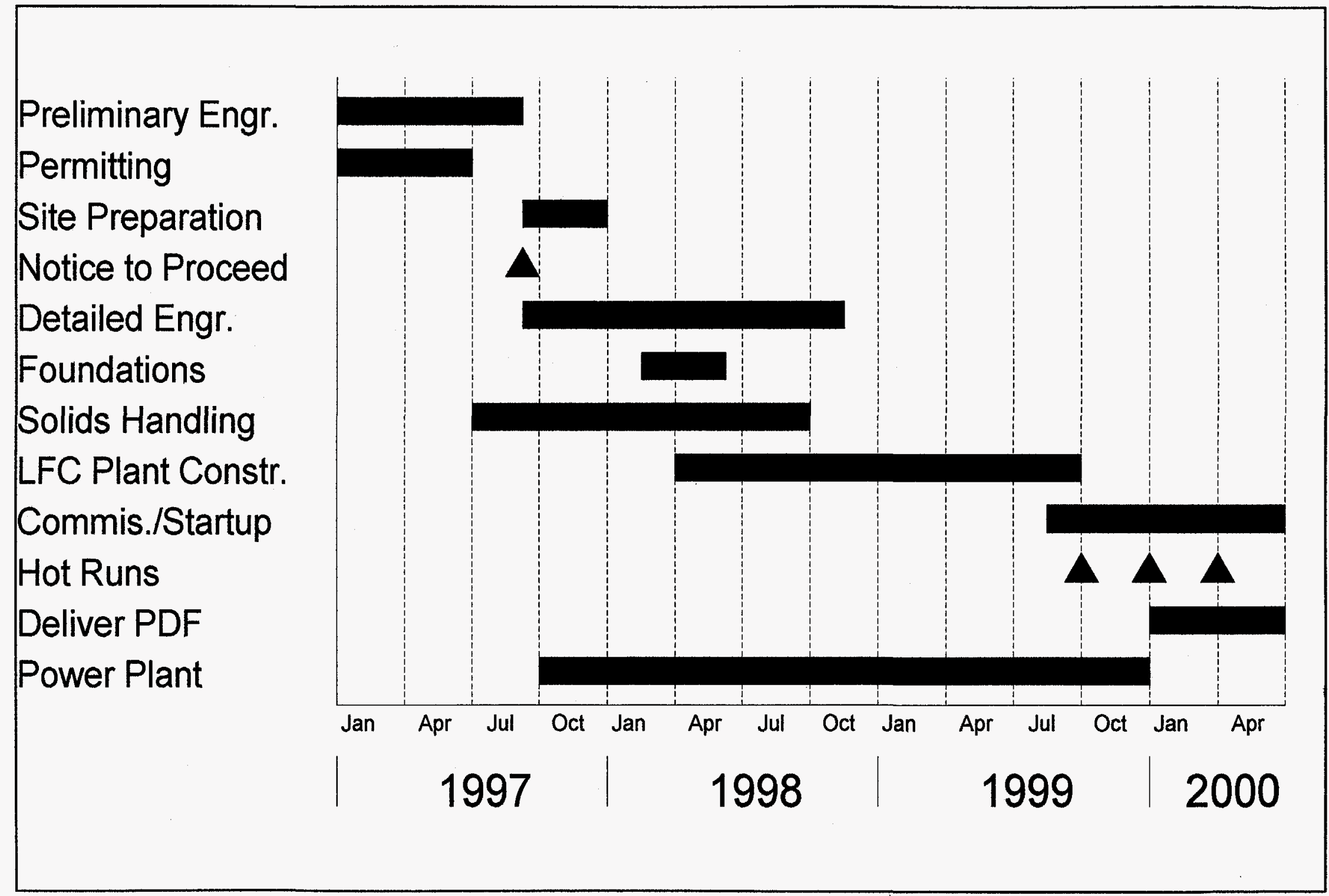




\section{Section 8.0 Project Economics}

\section{Overview}

A solid economic basis for the investment is crucial to the development of an LFC Commercial Plant. Capital costs, operating costs, product marketability and prices, and the impact of project financing are major factors affecting plant economics. These topics are discussed and evaluated in this section through the various case studies discussed below..

The base case for this Feasibility Study is the 15,000-metric-ton/day, three-unit North Rochelle LFC Plant with an independent $80-\mathrm{MW}$ cogeneration unit. Cogeneration is considered a corollary to the design basis document because significant quantities of fines will be produced in the large-scale LFC Process, and power generation and/or agglomeration for later use are the most economical possibilities. However, commercial plant economics do not include the cogeneration facility. It is assumed that the cogeneration unit is owned and operated by an independant third-party.

Project economics were calculated in two ways. First, the project was evaluated on a $100 \%$ equity basis. Sensitivities to operating cost, capital cost, revenue, tax credits and project timing were calculated for the base case. Independently, the project was then evaluated for the impact of project financing arrangements. The objective was to maximize the financeable debt ratio and determine the resulting return on investment.

\section{Capital Cost Estimate}

\section{Summary}

Capital costs greatly influence project economics, especially for a project as large as the three-unit LFC Commercial Plant contemplated by this Study. One of the primary objectives of this study, then, is to develop a reasonably accurate capital cost estimate in order to determine the economic viability of commercial LFC ventures.

Using the ENCOAL Plant design and newest available information as a base, the current estimates are built from scratch and do not rely on previous estimates. The accuracy of some component estimates is very close, while others such as CDL upgrading, PDF deactivation and finishing, are not as accurate. While some inaccuracies still exist, engineering work continues to refine capital estimates. As shown in Section 9.0, overall project economics are not overly sensitive to variations in capital estimates, which are well within sensitivities of $\pm 20 \%$.

Table 8.1 is a summary of the capital costs for the base case three-unit LFC plant. The bottom line capital cost for a full scale three module LFC plant is $\$ 475$ million. 


\section{Introduction}

While several previous estimates were developed by ENCOAL and TEK-KOL, they were not used for this Study. Instead, a design basis document for the engineering work was developed, and battery limits for the project were defined in light of the North Rochelle Mine location.

Within the overall project limits, a subset battery limits outline was developed for the division of work between TEK-KOL and MHI. Essentially, MHI's scope of work involved the LFC Plant and structures, and TEK-KOL's scope covered the balance of the off-sites, electrical systems, control systems and P\&IDs. Appropriate equipment estimates were developed; then contingencies, engineering and construction management were added to the estimate by taking a percentage of the base capital.

\section{Data}

Sections 5.0,6.0 and 7.0 describe in detail the basis for the capital estimate summarized in Table 8.1. The information for individual pieces of equipment is based either on vendor engineering quotes or actual purchases by the Zeigler-affilliated companies. Some of the off-site facilities are based on engineering studies done for the North Rochelle Mine. For the LFC Plant and structure estimate developed by $\mathrm{MHI}$, preliminary engineering has been done and an estimate developed independently in U.S. dollars. PDF quenching, deactivation, cooling and finishing were added to the MHI estimate according to the battery limits outline.

Some assumptions had to be made to proceed with the design and estimating work; most of the engineering assumptions are contained in the design basis documents. The following list also pertains specifically to the capital cost estimates:

1. Construction management for the project will include MHI and TEK-KOL support and a subcontractor. These costs are assumed to be $4 \%$ of total capital.

2. Engineering will be done by a team of TEK-KOL engineers and a contract engineering, procurement and construction group, like $\mathrm{MHI}$, and is assumed to be $9 \%$ of total capital.

3. The accuracy of the estimate does not require the addition of contingencies to the single LFC plant total capital. However, the estimate for the combination of three units was made with less information than would have been prefered, so $\$ 10$ million is allowed for contingencies for this case

4. The North Rochelle Mine is assumed to be in place and in production when the LFC Commercial Plant construction commences. 
5. Design and construction will take 36 months. A non-overlap six-month lead is assumed for the design work.

6. All three LFC units are constructed at the same time.

7. The LFC plants are essentially stand-alone facilities but do rely on the mine for raw coal storage, PDF loadout and water supply facilities.

\section{Conclusions}

A detailed capital cost estimate has been completed for a three module 15,000 metric ton-per-day commercial LFC plant at the North Rochelle Mine in Wyoming's Powder River Basin. These estimates are sufficiently accurate to support economic evaluations for a commercial plant venture, including financial participation options. A list of assumptions specific to the capital cost estimates has been presented.

Table 8.1: Capital Cost Summary

\begin{tabular}{|c|c|}
\hline Item & Capital Cost (SMM) \\
\hline Main LFC Facilites & 319 \\
\hline Support Facilities & 37 \\
\hline Flue Gas Scrubbing & 16 \\
\hline CDL Upgrading & 19 \\
\hline Environmental & 9 \\
\hline Engineering \& Other & 75 \\
\hline Total (\$MM) & 475 \\
\hline
\end{tabular}

\section{Operating Cost Model}

\section{Summary}

Economic benefits from an LFC Commercial plant are derived from the margin in value between a raw, unprocessed coal and the upgraded products, making an LFC plant dependent on the cost of feed coal. In fact, this is the largest single operating cost item. For this study, market prices for North Rochelle coal are used. The balance of the operating costs for the full-scale, three-unit LFC 
Commercial Plant are developed from scratch using the ENCOAL Plant as the basis. Labor rates and productivity expectations are based on ENCOAL experience in Wyoming. Assumed to be a standalone facility, the Commercial Plant does not rely on the adjacent North Rochelle Mine for operating or administrative assistance. The total estimated operating cost is $\$ 9.00 /$ ton of feed coal including the cost of feed coal, chemical supplies, maintenance and labor.

\section{Introduction}

A spreadsheet has been created to model the operating costs for the Commercial Plant. The model is combined with the economics spreadsheet to eliminate hand entry of data from one model to the other. An input data sheet is provided for all cost variables. These variables are used to calculate annual operating costs for the 30-year life of the project in an output data sheet. Project economics and financial evaluations use this data directly. In general, actual costs for chemicals, parts and supplies, labor and utilities are used from ENCOAL's operating experience. These are apportioned on the basis of throughput, number of people, capital cost and other factors as appropriate to arrive at the Commercial Plant costs.

\section{Data}

A summary of the cost categories is presented in Table 8.2. Permanent employment of 80 operating technicians and 22 staff is anticipated, and periodic contract assistance is allowed for major turnarounds. Maintenance has been assumed to be $2.5 \%$ of the major installed equipment cost.

Table 8.2: Operating Costs at Full Production

\begin{tabular}{|l|r|r|}
\hline & Operating Cost (SMM/Year) \\
\hline Feed Coal & Tear 2001 Dollars) \\
\hline Labor and Staff & 26.0 \\
\hline Supplies and Services & 7.2 \\
\hline Chemicals & 9.2 \\
\hline Utilities and Fuel & 5.4 \\
\hline \multicolumn{2}{|}{ Total Per Year (SMM) } & 4.8 \\
\hline
\end{tabular}




\section{Conclusions}

A detailed evaluation of the expected operating costs for the full-scale, three-unit plant has been completed. A computer model has been developed and integrated with the economics model. Comparison with previous estimates shows very good agreement, and the current estimate has been independently developed based on the latest ENCOAL Plant operating experience.

\section{Economic Assessment}

\section{Summary and Introduction}

A financial model was constructed using a spreadsheet to evaluate the project's financial viability. The key measurements utilized for internal evaluation are Internal Rate of Return (IRR) and Net Present Value (NPV). The significant assumptions relating to the financial analyses are listed in Table 8.3. The term "base case" refers to the three-module plant with 15,000 -metric ton/day capacity, excluding the synthetic fuel tax credit (29c tax credit). The IRR and NPV are most sensitive to revenue and to a lesser degree, capital investment. Operating costs variations had only a slight effect on IRR or NPV. The unleveraged IRR on the base case of around $15 \%$ is encouraging given the project's upfront capital requirements, long construction period, and 30-year project life. The project does generate impressive after-tax cash flows (ATCF's) with payback on the base case of less than 9 years from plant startup and cumulative ATCF's over 30 years, exceeding $\$ 2$ billion.

The base case unleveraged IRR will change as capital costs and revenue estimates are refined. The probability of reaching the $18 \%$ to $20 \%$ range for IRR is good, given a combination of lower capital costs and increased revenues. An increase in revenue of $10 \%$ coupled with a decrease in capital cost of $10 \%$ would provide an unleveraged IRR in excess of $18 \%$.

A possible upside to the base case is utilization of the non-conventional fuel tax credit commonly referred to as $29 \mathrm{c}$. This tax credit is calculated by converting PDF and CDL to a Barrel of Oil equivalent (BOE) base and then applying a rate per BOE. The addition of $29 \mathrm{c}$ to the base case evaluation adds over $15 \%$ to the unleveraged IRR, and more than doubles the project NPV. This positive financial impact would ease the financing of the project, and add greatly to the potential of building the first U.S. LFC Plant.

\section{Conclusions}

Overall, the base case looks strong on the basis of IRR and NPV with a good probability of improvement as the capital and revenue estimates are refined. The ATCF's are impressive with a payback period of less than 9 years. (See Table 8.4) The inputs to the model that are the least sensitive are the direct operating costs. The revenue is most sensitive variable, and the capital is somewhere in the middle. The ability of the project to qualify for the $29 \mathrm{c}$ tax credit is an unknown and should be resolved in the near future. The evaluation is subject to normal market risks on the revenue side with the chief area of opportunity being market values for the CDL product stream. 


\section{Table 8.3 \\ SIGNIFICANT ASSUMPTIONS}

- Project has a 30-year life from commissioning.

- Project assumes power plant is constructed, owned, and operated by a third party.

- Discount rate $12 \%$ on after cash cash flows for NPV calculations.

- Utility market volume is $80 \%$, steel industry $20 \%$ of total PDF volume.

- Escalation equals inflation (3\%) for revenue.

- Initial capital costs for construction - \$475 million.

- Construction timeframe - 20-24 months from notice to proceed.

- Regular tax rate for FIT (35\%).

Table 8.4: Commercial Plant Economics Summary

\begin{tabular}{|l|c|}
\hline \hline & Base Case \\
\hline IRR - Unleveraged & $\approx 15 \%$ \\
\hline $\mathrm{NPV}_{12}$ & $\approx \$ 169$ Million \\
\hline Total Capital Investment - (Excludes Capitalized Interest) & $\$ 475$ Million \\
\hline $\begin{array}{l}\text { Operating Cost } \\
\text { \$/Ton Feedstock }\end{array}$ & $\$ 9.00$ \\
\hline $\begin{array}{l}\text { Payback Period } \\
\text { Measured from Start-up) }\end{array}$ & 9 years \\
\hline Cumulative After Tax Cash Flow & $>\$ 2$ Billion \\
\hline
\end{tabular}




\section{Section 9.0 Project Risk Assessment}

\section{Technical Risk}

\section{Summary and Introduction}

Throughout this report, the discussions have made comparisons to the existing 1,000-ton/day ENCOAL Plant. This near-commercial-size plant was built and operated for the stated objective of "furthering the development of commercial LFC plants." More than any other single factor, $4 \frac{1}{2}$ years of successful operation of the ENCOAL Plant reduce the risks in scaling up the LFC processing unit to 5,000-metric tons/day. TEK-KOL believes the overall risk associated with the first commercial plant is reasonably low and is willing to make process guarantees on that basis.

\section{Factors Reducing Risk}

A number of other factors reduce the technical risk associated with the commercial venture. The ENCOAL Plant has been in operation periodically since June 1992, and runs approaching 90 days have been achieved with availability of $90 \%$ for the planned run period. Most of the equipment used in the ENCOAL Plant is commercially available with only minor modifications required to some units, and there are no prototype or first-of-a-kind devices. The combination of processing steps and equipment is unique, as is the control system used for the LFC Process, and these elements have been a resounding success at the ENCOAL Plant. More than 12,000 hours of operation have been logged processing 219,000 tons of Buckskin coal. Saleable PDF produced exceeds 75,500 tons and saleable CDL exceeds 189 tank cars.

The capital and operating costs developed in this Feasibiltiy Study should be fairly conservative. They are based heavily on the ENCOAL Plant, which went through a great deal of testing and modification in the early years. This resulted in more labor and maintenance effort than a continuously operating commercial plant should require. Larger, more cost-effective equipment may be available for some process steps when it is time to actually build the commercial plant. This has not been considered in these estimates; instead, the current basis is the largest unit currently offered by the ENCOAL Plant manufacturers. In short, the capital and operating costs have not been optimized.

As pointed out in Section 5.3, capital cost savings could result from more extensive integration of the LFC plant facilities with the mine or customer facilities depending on the LFC plant location and timing of construction. In some cases, the final rehydration and finishing steps may not be required, improving product quality and lowering capital costs significantly. The solid product would have to be inerted or used very quickly in this instance, since it would not be stable. These economics have not been considered in this evaluation. 
The protection of intellectual property is crucial to risk mitigation. It is TEK-KOL's intent to maintain a licenseable package that has value to others. This is being done through patent protection and development of a working proprietary control system.

\section{Factors Increasing Risk}

At the time of this Study, four areas require further work to minimize risk: the PDF deactivation step, the PDF finishing step, CDL upgrading and use of the MHI combined dryer/pyrolyzer grate. All this work is currently underway, and equipment estimates for these process steps have been made on the basis of engineering studies, pilot testing and vendor claims.

PDF deactivation has been shown to be an essential process step in the ENCOAL Plant. A 6- by 30foot vibrating fluidized bed reactor built by Carrier Corporation is used in the ENCOAL Plant, and it will only handle $50 \%$ of rated plant throughput. It is the largest such unit made, and at 11 units for the commercial plant, not a practical choice. The current estimate is based on a 142-foot diameter Salem Furnace quiescent bed, but this is untested. Engineering studies are underway, and plans are to test alternate equipment to accomplish oxidative deactivation in the laboratory and at the ENCOAL Plant. Costs for the alternate equipment could go above or below the current estimate.

PDF finishing will occur in a humid-air contacting vessel and has been pilot tested at the ENCOAL Plant. It has also been accomplished in a batch operation by outdoor pile layering, which has been used to stabilize all the PDF shipped to ENCOAL's customers to date. The conditions required for final PDF finishing are fairly well known. Currently, ENCOAL has located suitable equipment and plans to modify the ENCOAL Plant in the next few months using a commercially available unit that can be applied to the larger commercial plant.

CDL upgrading has been the subject of engineering studies, and a laboratory pilot plant was used to demonstrate process feasibility. The unit operations in the process flow sheet, such as vacuum flash, distillation and solvent extraction, are well demonstrated in the industry. The estimate used for this Feasibility Study is factored from the estimate made for a proposed ENCOAL Plant modification project.

Use of the MHI circular grate instead of the proven Salem Furnace Company grate design entails some risk. MHI has quenched coke with one of their grates for many years at the Toho Gas Works in Nagoya, Japan, so mechanical reliability is not an issue. Other questions on the grate application have been addressed by engineering studies, but several issues involving the processing of nonagglomerating fine coal remain to be answered. To answer these and other questions, MHI has built a pilot-size grate, and construction and testing will be complete by the end of 1997 . There is a significant cost advantage in using the single grate, and if necessary, Salem equipment can serve as a fall back.

Many coals from around the world have been tested in the LFC Sample Production Unit at the TEKKOL Development Center in Perrysburg, Ohio. This pilot-scale unit has been calibrated to the 
ENCOAL Plant to give dependable answers on the performance of various coals' processing charactistics, except the effect of particle degradation. Some coals disintegrate when dried and pyrolyzed in the LFC Process. The impact of such an event would be a marked increase in the fines generated and possibly the requirement of an agglomeration step. While this would negatively affect costs, it is a well-known technology.

\section{Conclusions}

TEK-KOL believes that on balance the technical risks are reasonable for the LFC Commercial Plant. The factors affecting risk are fairly well known, and the ENCOAL Plant operating experience provides overwhelming evidence that the basic LFC Technology works. TEK-KOL and its partners plan to guarantee the LFC Process and equipment to alleviate potential investors' concerns.

\section{Product Revenue Risk}

The products' revenue risk centers around conformance with customer/market product specifications, the stability of product revenue over time, and the credit worthiness of expected customer base.

\section{Conformance with Customer Product Specifications}

It has been proven that PDF will burn very well, and that PDF is anywhere from less dusty than, to as dusty as ROM Powder River Basin coal. ENCOAL has also shown that it can produce stable PDF through a ground-spreading technique, and commercial shipments of PDF stabilized using that method showed no tendency toward self-heating. A faster mechanical stabilization process has recently been proven in trials run at the ENCOAL Plant, and a commercial-sized version is incorporated into the design of the LFC Commercial Plant.

\section{Specification Conformance}

While development of the CDL products is still in the early stages, it is possible, even conservatively, to predict considerable potential in marketing these products.

1. Crude cresylic acid - It is possible that the percentage of useful cresylics in the crude cresylic acid fraction could vary as a result of feedstock variability or fluctuations in process conditions. The value of the crude cresylic acid will be directly related to the concentrations of useful cresylics contained.

2. Pitch - This product is not expected to meet the specifications for finished anode pitch on its own. Since it will be a blend material, any deviation from the targeted specifications will reduce the portion of the blend made up of CDL pitch.

3. Refinery Feedstock - The biggest risk associated with this product is keeping the oxygen level low. High oxygen is not desirable in most refinery processes and the 
value could be substantially affected if it is not possible to sufficiently lower the oxygen through the solvent extraction process.

4. Oxygenated Middle Fraction - For purposes of this Study, this product has been valued based on a fuel application. The major risk of specifications nonconformance would be in the area of compatibility with other residual fuels. This risk area could be overcome by working with customers to develop systems to segregate this material. There will probably be greater potential associated with this product as catechol producers are identified and contacted. It should be noted that because of this risk, an extremely low price of $\$ 5.50 / \mathrm{bbl}$ has been assumed.

\section{Stability of Product Revenue Over Time}

The key to creating stable product revenue over time is to develop long-term contractual relationships with specific customers. It is believed that the majority of the revenue stream can be made predictable through long-term contracts. The product streams in particular that could be long-term contracted are PDF (utility market and metallurgical market), crude cresylic acid and pitch.

\section{PDF}

Historically, high percentages (70-80\%) of the total coal sold to the utility sector has been under long-term contract. With utility deregulation on the horizon, utilities have increased the portion of purchases made under short-term agreements and have generally shortened the contracting period for their longer term commitments. The average utility's objective is to keep the cost of coal purchased in line with market cost. Most of the PDF can be sold under long-term contract, but any contract will likely have periodic market reopeners. Therefore, PDF revenue over time will roughly track the value of competitive coals in the market place, which does fluctuate over time. The risk for the PDF portion of the revenue stream would be comparable to the price risk associated with a new coal mine.

\section{Products}

Much remains to be learned about the product markets of the industries that the CDL distilled product will be sold into. Declining coke oven production over time should lead to lower crude cresylic acid and pitch availability; this should translate into a stable market and upward price pressures for those CDL distillation products. Sales of both of these products under long-term sales agreements should be possible.

The market for the refinery feedstock should be a commodity priced market subject to short-term price fluctuations. Future pricing for this product should track price fluctuations in crude oil and gas oil. 
If the oxygenated middle distillate is sold as a fuel (potentially its lowest value) it should be possible to sell under long-term contracts, but product pricing would probably be subject to a market pricing mechanism for comparable fuels.

\section{Financial Risk}

A preliminary review of financial risk indicates that the three-module, 15,000-metric ton/day facility referred to as the base case will be an investment-grade project. The project has an unleveraged IRR in the $15 \%$ range. On a leveraged basis the project IRR will most likely be between 25 and $30 \%$ depending on the project's debt capacity. Utilizing a debt coverage ratio hurdle of 1.5 and a borrowing rate of $8.25 \%$, the debt equity ratio will probably settle between 65 and $80 \%$.

The project will definitely be viewed as "new technology" by the financial community given the 5-to-1 scale up; however, the large-scale demonstration to date at the ENCOAL Plant is certainly an advantage. When financing is arranged, it is expected that the tenure of the debt will range between 8 and 10 years with the total door-to-door debt financing in the 14 to 15 year range. Given the long tenure required for this project, the most likely lenders will be the export credit agencies and the export/import banks. These lenders offer below-market rates and significant percentage of project financing.

Overall, the ability to finance the project is high, and considerable effort will be expended to allocate project risk in such a way as to attract quality debt financing. 


\section{References}

1. "The ENCOAL Project: Initial Commercial Shipment and Utilization of Both Solid and Liquid Products;" Topical Report, Report No. DOE/MC/27339-4088. ENCOAL Corporation, March 1995.

2. "Preliminary Report of EPDC PDF Laboratory Combustion Test Results," March 1995.

3. S.A. Johnson, B.A. Knottnerus, "Results of the PDF Test Burn at Clifty Creek Station," U.S. Department of Energy Topical Report, October 1996.

4. "ENCOAL Project Final Report," U.S. Department of Energy Report, July 1997. 


\section{GLOSSARY}

\begin{tabular}{|c|c|}
\hline ASME & American Society of Mechanical Engineers \\
\hline BS\&W & Basic Sediment \& Water \\
\hline Btu & British Thermal Units \\
\hline $\mathrm{CDL}$ & Coal Derived Liquid \\
\hline $\mathrm{CH}_{4}$ & Methane \\
\hline $\mathrm{CO}$ & Carbon Monoxide \\
\hline $\mathrm{CO}_{2}$ & Carbon Dioxide \\
\hline DOE & U.S. Department of Energy \\
\hline ENCOAL & $\begin{array}{l}\text { ENCOAL Corporation, wholly-owned subsidiary of } \\
\text { Bluegrass Coal Development Company }\end{array}$ \\
\hline ESP & Electrostatic Precipitators \\
\hline${ }^{0} \mathrm{~F}$ & Degrees Fahrenheit \\
\hline $\mathrm{ft}$. & Feet \\
\hline $\mathrm{ft}^{2}$ & Square Feet \\
\hline HP & Horsepower \\
\hline $\mathrm{H}_{2} \mathrm{O}$ & Water \\
\hline $\mathrm{H}_{2} \mathrm{~S}$ & Hydrogen Sulfide \\
\hline in. & Inches \\
\hline Kellogg & The M. W. Kellogg Company \\
\hline $\mathrm{lb} / \mathrm{hr}$ & Pounds per Hour \\
\hline LFC Technology & Liquid From Coal Technology \\
\hline $\mathrm{MM} \mathrm{Btu} / \mathrm{hr}$ & Million British Thermal Units per Hour \\
\hline $\operatorname{Max}$ & Maximum \\
\hline MSHA & Mine Safety and Health Administration \\
\hline $\mathrm{NO}_{\mathrm{x}}$ & Nitrogen Oxides \\
\hline $\mathrm{O}_{2}$ & Oxygen \\
\hline PDF & Process Derived Fuel \\
\hline PLC & Programmable Logic Controller \\
\hline$\%$ & Percent \\
\hline $\mathrm{pH}$ & Measure of alkalinity and acidity on a scale of 0 to 14 \\
\hline psia & Pounds per Square Inch Absolute \\
\hline psig & Pounds per Square Inch Gauge \\
\hline RPM & Rotations per Minute \\
\hline SMC & $\begin{array}{l}\text { SMC Mining Company, renamed Bluegrass Coal Development } \\
\text { Company, wholly owned subsidiary of Zeigler Coal Holding Company }\end{array}$ \\
\hline $\mathrm{SO}_{2}$ & Sulfur Dioxide \\
\hline $\mathrm{SO}_{\mathrm{x}}$ & Sulfur Oxides \\
\hline turnkey & $\begin{array}{l}\text { Subcontracting method that includes design, furnishing and installation } \\
\text { responsibility }\end{array}$ \\
\hline vol & Volume \\
\hline
\end{tabular}

